\title{
GATA4-targeted compound exhibits cardioprotective actions against doxorubicin-induced toxicity in vitro and in vivo: establishment of a chronic cardiotoxicity model using human iPSC-derived cardiomyocytes
}

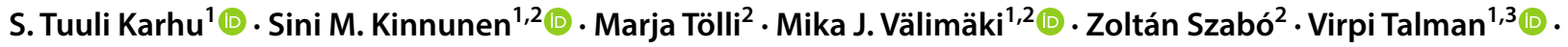 \\ Heikki Ruskoaho ${ }^{1,2}$ iD
}

Received: 28 October 2019 / Accepted: 9 March 2020 / Published online: 17 March 2020

(c) The Author(s) 2020

\begin{abstract}
Doxorubicin is a widely used anticancer drug that causes dose-related cardiotoxicity. The exact mechanisms of doxorubicin toxicity are still unclear, partly because most in vitro studies have evaluated the effects of short-term high-dose doxorubicin treatments. Here, we developed an in vitro model of long-term low-dose administration of doxorubicin utilizing human induced pluripotent stem cell-derived cardiomyocytes (hiPSC-CMs). Moreover, given that current strategies for prevention and management of doxorubicin-induced cardiotoxicity fail to prevent cancer patients developing heart failure, we also investigated whether the GATA4-targeted compound 3i-1000 has cardioprotective potential against doxorubicin toxicity both in vitro and in vivo. The final doxorubicin concentration used in the chronic toxicity model in vitro was chosen based on cell viability data evaluation. Exposure to doxorubicin at the concentrations of $1-3 \mu \mathrm{M}$ markedly reduced (60\%) hiPSC$\mathrm{CM}$ viability already within $48 \mathrm{~h}$, while a 14-day treatment with $100 \mathrm{nM}$ doxorubicin concentration induced only a modest 26\% reduction in hiPCS-CM viability. Doxorubicin treatment also decreased DNA content in hiPSC-CMs. Interestingly, the compound 3i-1000 attenuated doxorubicin-induced increase in pro-B-type natriuretic peptide (proBNP) expression and caspase-3/7 activation in hiPSC-CMs. Moreover, treatment with 3i-1000 for 2 weeks (30 mg/kg/day, i.p.) inhibited doxorubicin cardiotoxicity by restoring left ventricular ejection fraction and fractional shortening in chronic in vivo rat model. In conclusion, the results demonstrate that long-term exposure of hiPSC-CMs can be utilized as an in vitro model of delayed doxorubicin-induced toxicity and provide in vitro and in vivo evidence that targeting GATA4 may be an effective strategy to counteract doxorubicin-induced cardiotoxicity.
\end{abstract}

Keywords Doxorubicin · Cardiotoxicity $\cdot$ Human induced pluripotent stem cell-derived cardiomyocytes · Transcription factors $\cdot$ GATA4-targeted compounds · Cardioprotective

\section{Introduction}

S. Tuuli Karhu and Sini M. Kinnunen contributed equally to this work.

Electronic supplementary material The online version of this article (https://doi.org/10.1007/s00204-020-02711-8) contains supplementary material, which is available to authorized users.

Heikki Ruskoaho

heikki.ruskoaho@helsinki.fi

Drug Research Program and Division of Pharmacology and Pharmacotherapy, Faculty of Pharmacy, University of Helsinki, P.O. Box 56, 00014 Helsinki, Finland
Cardiotoxicity is a well-recognized devastating adverse outcome related to cancer therapy and can lead to longterm morbidity (Senkus and Jassem 2011). Its prevalence is increasing due to improved long-term survival of cancer patients. One of the most commonly used groups of

2 Department of Pharmacology and Toxicology, Institute of Biomedicine, University of Oulu, Oulu, Finland

3 National Heart and Lung Institute, Imperial College London, London, UK 
anticancer drugs are the anthracyclines (e.g. doxorubicin, daunorubicin and idarubicin) which may cause acute cardiac damage that can be reversible, but more commonly cause late-onset toxicity that leads to heart failure. Anthracycline cardiotoxicity is dose-dependent with the heart failure incidence rates ranging from 0.14 to $48 \%$ (Conway et al. 2015). If baseline cardiotoxicity risk is high, a prophylactic cardioprotective treatment with angiotensin-converting enzyme inhibitors, angiotensin II receptor blockers, $\beta$-blockers and/ or statins should be considered (Corremans et al. 2019; Zamorano et al. 2016). Other strategies to prevent left ventricular dysfunction and heart failure induced by anthracyclines include reduction in the cumulative dose and use of continuous infusions to decrease peak plasma levels, liposomal formulations and less toxic analogues of anthracyclines as well as FDA-approved cardioprotective agent dexrazoxane (Zamorano et al. 2016). Unfortunately, none of these strategies is efficacious enough to prevent a subset of cancer patients developing heart failure.

The exact mechanisms of anthracycline-induced cardiotoxicity are still unclear, but may involve oxidative stress, interaction with DNA topoisomerase II beta, calcium dysregulation, iron accumulation, mitochondrial damage, structural changes, and premature senescence as well as activation of immune system (Maejima et al. 2008; Octavia et al. 2012; Renu et al. 2018; Rochette et al. 2015; Zhang et al. 2012). Anthracyclines (Aries et al. 2004; Bien et al. 2007; Esaki et al. 2008; Kim et al. 2003; Kobayashi et al. 2006, 2010; Koka et al. 2010; Riad et al. 2008) along with ischemia (Suzuki et al. 2004) have been shown to induce apoptosis and downregulation of transcription factor GATA4 in the myocardium. Increased apoptosis has also been observed in adult cardiomyocytes in GATA4 knock-out mice and in mice with reduced GATA4 levels (Bisping et al. 2006; Oka et al. 2006) as well as in neonatal cardiomyocytes when GATA4 has been depleted by adenoviral antisense transcripts (Aries et al. 2004). In agreement with these findings, GATA4 overexpression in vivo by intramyocardial delivery of GATA4 adenoviral vector prevented myocardial infarction-induced apoptosis and adverse remodelling in rats (Rysä et al. 2010). Accordingly, overexpression of GATA4 in transgenic mice (Kobayashi et al. 2006) or by adenovirus-mediated gene transfer in vitro in neonatal cardiomyocytes and HL-1 cells prevented anthracycline-induced apoptosis (Aries et al. 2004; Kim et al. 2003; Kobayashi et al. 2006). The mechanisms of doxorubicin-induced decrease in GATA4 protein levels may involve downregulation of GATA4 gene expression (Park et al. 2011) or caspase-1-dependent depletion of GATA4 protein levels (Aries et al. 2014). On the other hand, GATA4 is a transcriptional regulator of the anti-apoptotic genes Bcl-xL (Aries et al. 2004; Kitta et al. 2003; Park et al. 2007) and Bcl-2 (Kobayashi et al. 2006) for which GATA4 binding activity and Ser-105 phosphorylation are required
(Kobayashi et al. 2006). Overall, these findings demonstrate the significance of GATA4 for cell survival signalling.

One reason for the lack of full understanding of the mechanisms of doxorubicin cardiotoxicity may be that traditional preclinical models are not appropriate or sufficiently clinically relevant (Madonna et al. 2015). The translatability of results from in vitro and in vivo models to human is limited as these models are unable to reproduce the complex pathophysiology of human disease. For instance, animal models do not generally take into consideration ageing or comorbidities that aggravate drug-induced cardiotoxicities in clinical situations. Moreover, most in vitro studies have evaluated the effects of short-term high-dose doxorubicin treatments (Corremans et al. 2019). Additionally, due to interspecies differences, in vitro and in vivo animal models do not predict accurately the toxic effects on human heart. Thus, better experimental models of doxorubicin cardiotoxicity are needed to more appropriately simulate clinical circumstances as well as the actions of potential cardioprotective agents.

The present study had two main aims. First, we aimed to establish an in vitro model of long-term low-dose administration of doxorubicin utilizing human induced pluripotent stem cell-derived cardiomyocytes (hiPSC-CMs). Cell viability was studied with the 3-(4,5-dimethylthiazol-2-yl)2,5-diphenyltetrazolium bromide (MTT) assay. High-content analysis (HCA) was used to study changes in DNA content, transcription factor GATA4 levels, expression of pro-B-type natriuretic peptide (proBNP), as well as caspase activation. Additionally, to compare different cardiomyocyte types, toxicity was studied in both hiPSC-CMs and primary neonatal rat ventricular myocytes (NRVMs). Second, as we have recently described a novel family of small-molecule compounds that affect the protein-protein interaction of transcription factors GATA4 and NKX2-5 and improve cardiac function in experimental models of myocardial infarction and hypertension (Ferreira et al. 2017; Kinnunen et al. 2018; Välimäki et al. 2017), we aimed to investigate if the lead compound 3i-1000 has cardioprotective potential against doxorubicin cardiotoxicity in vitro and in vivo.

\section{Materials and methods}

\section{Reagents}

Cell culture media, supplements and reagents were purchased from Gibco (Thermo Fisher Scientific, Paisley, UK). Bovine serum albumin (BSA), insulin-transferrin-sodium selenite media supplement, sodium pyruvate, pancreatin, 4',6-diamidino-2-phenylindole (DAPI), and 3-(4,5-dimethylthiazol-2-yl)-2,5-diphenyltetrazolium bromide (MTT) were purchased from Sigma-Aldrich 
(Steinheim, Germany). Collagenase type 2 was purchased from Worthington Biochemical Corporation (Lakewood, New Jersey, USA). Growth Factor-Reduced Matrigel ${ }^{\circledR}$ was bought from Corning (Bedford, Massachusetts, USA) and gelatin from Merck Millipore (Darmstadt, Germany). Doxorubicin hydrochloride for in vitro studies as well as small-molecule inhibitors Y-27632, CHIR99021, and WntC59 were acquired from Tocris Bioscience (Bristol, UK). Doxorubicin hydrochloride for the in vivo study was from Sigma-Aldrich. The small-molecule compound inhibiting GATA4 and NKX2-5 interaction (3i-1000; compound 3 in Välimäki et al. 2017), $N$-[4-(diethylamino)phenyl]-5-methyl3-phenylisoxazole-4-carboxamide was purchased from Pharmatory LTD (Oulu, Finland). The purity of the compound (minimum $>95 \%$ ) was determined by HPLC/MS and ${ }^{1} \mathrm{H}$ NMR, and the possibility of aggregation of the compound was excluded (Välimäki et al. 2017). The primary antibodies used in immunofluorescence stainings were monoclonal rabbit anti-GATA4 (Cell Signaling Technology \#36966), monoclonal mouse anti-proBNP (Abcam \#ab13115), monoclonal mouse anti- $\alpha$-actinin (Sigma-Aldrich \#A7811), and polyclonal rabbit anti-cardiac troponin T (Abcam \#ab45932). The secondary antibodies used were all purchased from Life Technologies (Eugene, Oregon, USA): Alexa Fluor 488 goat anti-mouse $\lg$ (\#A11029), Alexa Fluor 488 goat anti-rabbit $\operatorname{lgG}$ (\#A11034), Alexa Fluor 647 goat anti-mouse $\operatorname{lgG}$ (\#A21236), and Alexa Fluor 647 donkey anti-rabbit $\lg$ G (\#A31573). eBioscience ${ }^{\mathrm{TM}}$ Brefeldin A Solution (1000X) and CellEvent ${ }^{\mathrm{TM}}$ Caspase-3/7 Green Detection Reagent were from Invitrogen (Carlsbad, California, USA). The primary antibodies used in western blotting were polyclonal rabbit anti-GATA4 (Santa Cruz Biotechnology \#sc-9053), polyclonal rabbit anti-phospho-p38 (Cell Signaling Technology \#9211), polyclonal rabbit anti-p38 (Cell Signaling Technology \#9212), and monoclonal mouse anti-GAPDH (Merck Millipore \#MAB374). The secondary HRP-linked antibodies anti-rabbit IgG (\#7074) and anti-mouse IgG (\#7076) were purchased from Cell Signaling Techonology. Quantitative real-time polymerase chain reaction (RT-PCR) oligos were from Sigma-Aldrich.

\section{Cell cultures}

Long-term toxicity was studied in hiPSC-CMs. Acute toxicity was studied in both hiPSC-CMs and primary NRVMs. Cell cultures were maintained at $37{ }^{\circ} \mathrm{C}$ in a humidified atmosphere of $5 \% \mathrm{CO}_{2}$. To investigate if the compound 3i-1000 is cardioprotective against doxorubicin-induced toxicity, the cells were exposed simultaneously to both doxorubicin and 3i-1000. The selection of doxorubicin concentrations was based on plasma concentrations detected in patients undergoing treatment (Creasey et al. 1976; Greene et al. 1983; Muller et al. 1993; Speth et al. 1987). The selection of 3i-1000 concentrations was based on previous studies investigating the efficacy and toxicity of the compound in vitro (Karhu et al. 2018; Välimäki et al. 2017). For compound exposures doxorubicin, 3i-1000, and equivalent vehicle dilutions were made separately in the growth medium. Compound exposures were started by aspirating the old growth media and adding first the media containing 3i-1000 (or equivalent volume concentration of dimethylsulfoxide; DMSO) to the cells. Cells were incubated at $37{ }^{\circ} \mathrm{C}$ for 10-15 min after which the medium containing doxorubicin (or equivalent volume concentration of DMSO) was also added to the cells. During long-term exposures, the media were replaced with fresh growth media (containing doxorubicin and/or 3i-1000) every 3-4 days.

\section{Human induced pluripotent stem cell-derived cardiomyocytes}

The iPS(IMR90)-4 line (Yu et al. 2007) was purchased from WiCell (Madison, Wisconsin, USA). The stem cells were cultured in Essential $8^{\mathrm{TM}}$ medium (E8) on six-well plates coated with Matrigel ${ }^{\circledR}$ (1:50). For passaging, the cells were dissociated with Versene ${ }^{\circledR}$ and resuspended in E8 containing $10 \mu \mathrm{M}$ ROCK inhibitor Y-27632. The cells were grown until 80-95\% confluent. Cardiomyocytes were produced from hiPSCs using small-molecule induction, as described earlier (Burridge et al. 2014; Karhu et al. 2018). Differentiation was started by adding $6 \mu \mathrm{M}$ CHIR99021 in RPMI 1640 medium supplemented with B-27 without insulin (RB-ins) to the cells (day 0). After 24 h, CHIR99021 was removed and replaced with fresh RB-ins (day 1). On day 3, the medium was changed to RB-ins containing $2.5 \mu \mathrm{M}$ Wnt$\mathrm{C} 59$ for $48 \mathrm{~h}$. From day 5 to 11, the cells were maintained in RB-ins. To purify the cardiomyocyte cultures, on day 11 and 13, the cells were fed with RPMI 1640 without glucose with B-27 supplement. From day 15 onwards, the cells were maintained in RPMI 1640 supplemented with B-27 $(\mathrm{RB}+\mathrm{ins})$. Beating hiPSC-CMs were dissociated between days 15 and 17 by incubating them in cell dissociation solution containing $40 \%$ enzyme-free cell dissociation buffer, 40\% RPMI 1640 and 20\% trypsin-EDTA (final trypsin concentration $0.01 \%$ ) for $7-8 \mathrm{~min}$. Trypsin was inactivated with $\mathrm{RB}+$ ins supplemented with $10 \%$ foetal bovine serum (FBS). After centrifugation the cells were suspended in $\mathrm{RB}+$ ins with $10 \%$ FBS containing $10 \mu \mathrm{M}$ ROCK inhibitor Y-27632 and seeded at 17,000-20,000 cells/well on gelatin-coated 96-well plates. In general, differentiation yielded almost pure $(>95 \%)$ cardiomyocyte cultures indicating high differentiation efficiency. In the experiments, only differentiation batches that were $>95 \%$ pure cardiomyocyte cultures were used. The cells were let to attach for 2 days, after which they were maintained in RB + ins (without FBS) for 
approximately 1 week before treatments. For compound exposures, RB + ins (without FBS) was used.

\section{Primary cardiomyocytes}

Primary cultures of NRVMs were prepared from 1 to 3 day-old Wistar rats, as described earlier (Tölli et al. 2014). Animals were sacrificed by decapitation. Ventricles were dissected and cut into small pieces, which were then enzymatically digested by incubating them for $1-1.5 \mathrm{~h}$ at $37^{\circ} \mathrm{C}$ under $600 \mathrm{rpm}$ shaking conditions in a solution containing $100 \mathrm{mM} \mathrm{NaCl}, 10 \mathrm{mM} \mathrm{KCl}, 1.2 \mathrm{mM}$ $\mathrm{KH}_{2} \mathrm{PO}_{4}, 4.0 \mathrm{mM} \mathrm{MgSO}$, $50 \mathrm{mM}$ taurine, $20 \mathrm{mM}$ glucose, $10 \mathrm{mM}$ 4-(2-hydroxyethyl)-1-piperazineethanesulfonic acid (HEPES), $2 \mathrm{mg} / \mathrm{ml}$ collagenase type $2,2 \mathrm{mg} / \mathrm{ml}$ pancreatin, $100 \mathrm{U} / \mathrm{ml}$ penicillin, and $100 \mu \mathrm{g} / \mathrm{ml}$ streptomycin. The cell suspension was collected and centrifuged for $5 \mathrm{~min}$ at $160 \times \mathrm{g}$. The supernatant and the top layer of the pellet were discarded and the isolated cardiac cells were resuspended in Dulbecco's Modified Eagle Medium/Nutrient Mixture F-12 (DMEM/F12) supplemented with 10\% FBS, 100 U/ $\mathrm{ml}$ penicillin, and $100 \mu \mathrm{g} / \mathrm{ml}$ streptomycin. To reduce the number of contaminating non-myocytes $(25-45 \%$ on day 3 after cell isolation), the cells were pre-plated onto cell culture flasks and let attach for 45-60 min in cell culture conditions. Unattached cells (enriched cardiomyocytes) were collected with the medium and seeded at 30,000-40,000 cells/ well in gelatin-coated 96-well plates. Next day, the medium was changed to complete serum free medium (CSFM; DMEM/F-12 supplemented with $2.5 \mathrm{mg} / \mathrm{ml}$ BSA, $5 \mu \mathrm{g} /$ $\mathrm{ml}$ insulin, $5 \mu \mathrm{g} / \mathrm{ml}$ transferrin, $5 \mathrm{ng} / \mathrm{ml}$ selenium, $2.8 \mathrm{mM}$ sodium pyruvate, $0.1 \mathrm{nM}$ triiodo-L-thyronine (T3), $100 \mathrm{U} /$ $\mathrm{ml}$ penicillin, and $100 \mu \mathrm{g} / \mathrm{ml}$ streptomycin) for $24 \mathrm{~h}$ prior to compound treatments. For compound exposures, CSFM was used.

\section{Cell viability assay}

The cells were exposed to doxorubicin and/or 3i-1000 for 2-21 days and cell viability was quantified with MTT assay (Mosmann 1983). MTT was added to the cells at a final concentration of $0.5 \mathrm{mg} / \mathrm{ml}$ followed by $2 \mathrm{~h}$ incubation in cell culture conditions. The medium was aspirated and formed formazan crystals were solubilized in DMSO. Absorbance was measured at $550 \mathrm{~nm}$ and absorbance at $650 \mathrm{~nm}$ was subtracted as background.

\section{Automated fluorescence microscopy and high-content analysis}

The cells were exposed to doxorubicin and/or 3i-1000 for 1-14 days. For proBNP stainings, cells were additionally treated with Brefeldin A (1:1000) for $3 \mathrm{~h}$ prior to fixation.
Alternatively, to study caspase activation, the cells were incubated with $7 \mu \mathrm{M}$ caspase-3/7 detection reagent solution in phosphate-buffered saline (PBS) with 5\% FBS for $60 \mathrm{~min}$ at $37^{\circ} \mathrm{C}$ prior to fixation. The cells were fixed with $4 \%$ paraformaldehyde (PFA) for $15 \mathrm{~min}$ at room temperature (rt) and permeabilized with $0.1 \%$ Triton X-100 for $10 \mathrm{~min}$. Non-specific binding sites were blocked with $4 \%$ FBS in PBS for 45 min at $\mathrm{rt}$ after which the cells were incubated with anti-GATA4 (1:400) or anti-proBNP (1:500) antibody. Additionally, a primary antibody against $\alpha$-actinin (1:600) or cardiac troponin $\mathrm{T}(1: 800)$ was used to identify myocytes. After a 60-min incubation with primary antibodies at rt, the cells were washed $3 \times 5$ min with PBS followed by a 45 -min incubation with Alexa Fluor-conjugated secondary antibodies (1:200, with the exception of Alexa Fluor 647 anti-rabbit $1: 250)$ and DAPI $(1 \mu \mathrm{g} / \mathrm{ml})$ at $\mathrm{rt}$. The plates were imaged and analysed with CellInsight CX5 High-Content Screening Platform (Thermo Scientific) using a $10 \times$ objective (Olympus UPlanFL N 10x/0.3). For quantification, the cells were first identified based on DAPI fluorescence, which defined the nuclear area. Non-myocytes were excluded based on absence of $\alpha$-actinin/cardiac troponin T staining. The threshold for $\alpha$-actinin/cardiac troponin T fluorescence intensity was set manually in each experiment to allow optimal exclusion of non-myocytes. The data were collected only from $\alpha$-actinin/cardiac troponin T positive cells. The intensity of GATA4 staining was analysed within the nucleus. The intensity of proBNP staining was analysed in the perinuclear area defined by a 4-pixel ring around the nucleus. The threshold for proBNP positive cells was set manually in each experiment to adjust for minor variation in staining intensity. The intensity of fluorescent caspase-3/7 activity reporter was quantified within the nucleus. The threshold for caspase positive and caspase negative cells was also set manually in each experiment.

\section{Doxorubicin-induced cardiotoxicity in rats}

Doxorubicin was administered i.p. to 7 weeks old male Sprague Dawley rats with average weight $216 \mathrm{~g}$ (range 189-245 g) at the dose of $1 \mathrm{mg} / \mathrm{kg} /$ day for 10 days (Hayward and Hydock 2007). Control animals received an equivalent volume of saline. Based on previous experiments, and due to its rapid metabolism (Kinnunen et al. 2018), the compound 3i-1000 was administered i.p. at the dose of $15 \mathrm{mg} /$ $\mathrm{kg}$ two times a day for 2 weeks from week 7 to week 9. It was diluted to DMSO and administered to animals as 1:1 dilution in corn oil, control animals receiving DMSO with corn oil in equivalent volume. Transthoracic echocardiography was performed using the Vevo2100 high-frequency high-resolution linear array ultrasound system (FujiFilm VisualSonics, Toronto, Canada) and MS-250 transducer (13-24 MHz, axial resolution $75 \mu \mathrm{m}$, lateral resolution 
$165 \mu \mathrm{m})$ by a trained sonographer blinded to the treatments, as described previously (Jurado Acosta et al. 2017). Rats were sedated with isoflurane or anesthetized with ketamine $(50 \mathrm{mg} / \mathrm{kg}$, i.p.) and xylazine (10 mg/kg, i.p.). Using twodimensional imaging, a short axis view of the left ventricle (LV) at the level of the papillary muscles was obtained and a two-dimensionally guided $\mathrm{M}$-mode recording through the anterior and posterior walls of the LV were acquired. Endsystolic and end-diastolic LV dimensions (ESD and EDD) as well as the thickness of the interventricular septum and posterior wall were measured from the M-mode tracings. LV fractional shortening (FS) and ejection fraction (EF) were calculated from the M-mode LV dimensions using Eqs. 1 and 2:

$\mathrm{FS}(\%)=\{($ LVEDD - LVESD $) /$ LVEDD $\} \times 100$,

$\mathrm{EF}(\%)=\left\{(\mathrm{LVEDD})^{3}-(\mathrm{LVESD})^{3} / \mathrm{LVEDD}^{3}\right\} \times 100$

An average of three measurements of each variable were used. After echocardiographic measurements at 9 weeks, the terminally anesthetized animals were decapitated, hearts were excised, and the apex of left ventricle was immersed in liquid nitrogen and stored at $-70^{\circ} \mathrm{C}$ for further analysis.

\section{RNA isolation from LV tissue and RT-PCR}

The LV tissue was grinded in liquid nitrogen to powder, of which $1 / 3$ was used for total RNA isolation using guanidine thiocyanate- $\mathrm{CsCl}$ method (modified from Cathala et al. 1983). Shortly, tissue powder was homogenised in $3 \mathrm{ml}$ lysis buffer containing $4 \mathrm{M}$ guanidium thiocyanate, $0.1 \mathrm{M}$ Tris- $\mathrm{HCl}(\mathrm{pH} 7.5), 7 \% \beta$-mercaptoethanol and 1.0-2.0\% Na-lauroylsarcosine with Ultra-Turrax ${ }^{\circledR}\left(\right.$ IKA $\left.^{\circledR}\right)$ and cell debris was pelleted for $10 \mathrm{~min} 3000 \mathrm{rpm}(1791 \times g) 4{ }^{\circ} \mathrm{C}$. The supernatant containing RNA was stored in $-80{ }^{\circ} \mathrm{C}$ for further treatment. RNA was isolated by ultracentrifugation overnight through a $5.7 \mathrm{M} \mathrm{CsCl}$ cushion at $4{ }^{\circ} \mathrm{C}$. The resulting pellet was resuspended in lysis buffer and RNA was precipitated with $3 \mathrm{M}$ sodium acetate ( $\mathrm{pH}$ 5.2) (1/10 vol) and ice cold absolute ethanol $(3 \times \mathrm{vol})$ at least for $1 \mathrm{~h}$ at $-20{ }^{\circ} \mathrm{C}$. The precipitated RNA was pelleted by centrifugation for $15-20 \mathrm{~min} 12,000 \mathrm{rpm}(13,520 \times \mathrm{g})$ at $4{ }^{\circ} \mathrm{C}$ and washed with $70 \%$ ethanol in diethylpyrocarbonate (DEPC)-treated water followed by another centrifugation for 5-10 $\mathrm{min}$ as described above. The washing was repeated and RNA pellet was air dried before dissolving in DEPC- $\mathrm{H}_{2} \mathrm{O}$. For quantitative RT-PCR analyses, cDNA was synthesised from total RNA with a First-Strand cDNA Synthesis Kit (GE Healthcare Life Sciences) following the manufacturer's protocol. RNA was analysed by RT-PCR on an ABI 7300 sequence detection system (Applied Biosystems) using TaqMan chemistry. The results were quantified using $\Delta \Delta C_{T}$ method and normalised to 18S RNA quantified from the same samples. The following sequences of the primers and the fluorogenic probe were used in assay: atrial natriuretic peptide (ANP, forward:GAAAAGCAAACTGAGGGCTCTG, reverse:CCT ACCCCCGAAGCAGCT, probe: TCGCTGGCCCTCGGA GCCT) and B-type natriuretic peptide (BNP, forward: TGG GCAGAAGATAGACCGGA, reverse: ACAACCTCAGCC CGTCACAG, probe: CGGCGCAGTCAGTCGCTTGG).

\section{Protein extraction from LV tissue and western blot}

Two thirds of the ground LV tissue was homogenised in $4 \mathrm{ml}$ of lysis buffer $(20 \mathrm{mM}$ Tris, $10 \mathrm{mM} \mathrm{NaCl}, 0.1 \mathrm{mM}$ EDTA, $0.1 \mathrm{mM}$ EGTA, pH 8.0) containing protease and phosphatase inhibitors $(1 \mathrm{mM} \beta$-glycerophosphate, $1 \mathrm{mM}$ $\mathrm{Na}_{3} \mathrm{VO}_{4}, 10 \mu \mathrm{g} / \mathrm{ml}$ leupeptin, $10 \mu \mathrm{g} / \mathrm{ml}$ pepstatin, $10 \mu \mathrm{g} /$ $\mathrm{ml}$ aprotinin, $2 \mathrm{mM}$ benzamidine, $1 \mathrm{mM}$ phenylmethylsulfonyl fluoride, $50 \mathrm{mM}$ sodium fluoride, $1 \mathrm{mM}$ dithiothreitol). Of the homogenate, $0.8 \mathrm{ml}$ was used for total protein extraction and the rest for nuclear protein extraction. Then, $0.2 \mathrm{ml}$ of lysis buffer $(100 \mathrm{mM}$ Tris- $\mathrm{HCl}, 750 \mathrm{mM} \mathrm{NaCl}$, $5 \mathrm{mM}$ EDTA, $5 \mathrm{mM}$ EGTA, 5\% Triton X-100, $12.5 \mathrm{mM}$ sodium pyrophosphate, $5 \mathrm{mM} \beta$-glycerophosphate, $5 \mathrm{mM}$ $\mathrm{Na}_{3} \mathrm{VO}_{4}, \mathrm{pH}$ 7.5) was added into the total protein homogenate and vortexed for $30 \mathrm{~s}$. After a 20 -min centrifugation at $12,500 \mathrm{rpm}(14,670 \times g)$ at $4{ }^{\circ} \mathrm{C}$, the supernatant containing total proteins was collected. For nuclear protein extraction, the homogenate was divided into two sets, which were later combined. The homogenate was kept on ice for $15 \mathrm{~min}$ after which NP-40 was added at the final concentration of $0.6 \%$. Sample was vortexed vigorously for $15 \mathrm{~s}$ and centrifuged for $30 \mathrm{~s}$ at $12,500 \mathrm{rpm}(14,670 \times \mathrm{g})$ at $4{ }^{\circ} \mathrm{C}$. The pellet was suspended into buffer ( $20 \mathrm{mM}$ Hepes, $0.4 \mathrm{mM} \mathrm{NaCl}, 1 \mathrm{mM}$ EDTA, 1 mM EGTA, pH 8.0) including inhibitors mentioned above and the parallel samples were combined. The samples were then vortexed vigorously for $45 \mathrm{~min}$ at $4{ }^{\circ} \mathrm{C}$. After the final centrifugation at $12,500 \mathrm{rpm}$ for $5 \mathrm{~min}$ at $4{ }^{\circ} \mathrm{C}$, the supernatant containing nuclear proteins was collected. The protein concentrations were determined with the Bio-Rad Protein Assay. From each animal, $50 \mu \mathrm{g}$ of total protein or $20 \mu \mathrm{g}$ nuclear protein was resolved on $12 \%$ SDSPAGE gel and transferred onto nitrocellulose membrane. After blocking the nonspecific background in 5\% non-fat dry milk, the membranes were incubated with 1:1000 dilution of primary antibodies, except for anti-GAPDH, which was used at 1:100,000 dilution, at $4{ }^{\circ} \mathrm{C}$ overnight. After washing, the membranes were incubated for $1 \mathrm{~h}$ with an HRP-conjugated anti-rabbit or anti-mouse secondary antibody in 1:2000 dilution. The protein amounts were detected by enhanced chemiluminescence with ECL Plus reagents (RPN2132, Amersham Biosciences) followed by digitalization of chemiluminescence with Luminescent Imager Analyzer LAS-3000 (Fujifilm) and analysing with Quantity One 
software 4.6.6.Basic (Bio-Rad Laboratories). For a second immunoblotting, the membrane was stripped for $30 \mathrm{~min}$ at $60{ }^{\circ} \mathrm{C}$ in stripping buffer $(0.16 \mathrm{M}$ Tris- $\mathrm{HCl}, 6.5 \%$ SDS and $2.25 \% \beta$-mercaptoethanol), blocked and probed with antibodies as described above.

\section{Statistics}

In vitro results are expressed as mean from at least three independent experiments with error bars representing the standard error of the mean (SEM). For statistical analysis, non-normalized raw data was used. Statistical analyses were performed using IBM SPSS Statistics 24 software. Statistical significance was evaluated with randomized block ANOVA (experiment and treatment as factors) followed by Tukey's HSD. In vivo results are expressed as mean with error bars representing SEM. For the first series of in vivo results, Welch's $t$ test was used to compare groups $\mathrm{NaCl}$ and DOX at each time point separately. For the second series of in vivo results, Levene's test was used to analyse the equality of variances after which independent-samples $t$ test was used to compare groups $\mathrm{NaCl}+\mathrm{V}$ and $\mathrm{DOX}+\mathrm{V}$ or $\mathrm{DOX}+\mathrm{V}$ and DOX $+3 \mathrm{i}-1000$. Differences at the level of $P<0.05$ were considered statistically significant.

\section{Ethics}

Animal experiments were carried out in accordance with the 3R principles of the EU directive 2010/63/EU governing the care and use of experimental animals, and following local laws and regulations [Finnish Act on the Protection of Animals Used for Scientific or Educational Purposes (497/2013, Government Decree on the Protection of Animals Used for Scientific or Educational Purposes (564/2013)]. The protocols were approved by the national Animal Experiment Board of Finland (ESAVI-2010-03964/Ym-23).

\section{Results}

\section{Doxorubicin-induced chronic toxicity in hiPSC-CMs}

To study the long-term toxicity in vitro, hiPSC-CMs were exposed to doxorubicin for up to 21 days. Exposure to doxorubicin at concentrations of $1 \mu \mathrm{M}$ and $3 \mu \mathrm{M}$ markedly reduced hiPSC-CM viability already within $48 \mathrm{~h}$ (approximately $60 \%, P<0.001$; Fig. 1a). Treatment of hiPSCCMs with $300 \mathrm{nM}$ doxorubicin was less toxic but resulted in severe cytotoxicity within 21 days. On the other hand, a 14-day exposure to $100 \mathrm{nM}$ doxorubicin induced only a modest 26\% $(P=0.201)$ reduction in hiPSC-CM viability. Based on these results, doxorubicin at the concentration of $100 \mathrm{nM}$ for 14 days was chosen for further HCA experiments to explore long-term toxicity. To investigate the effects of the small-molecule compound 3i-1000 in hiPSC-CMs, the cells were exposed to the compound alone or in combination with doxorubicin for 7, 14, and 21 days (Fig. 1b). In the MTT assay, $3 \mathrm{i}-1000$ alone at $10 \mu \mathrm{M}$ concentration reduced hiPSCCM viability $34 \%(P=0.001), 50 \%(P<0.001)$ and $65 \%(P$ $<0.001)$ after 7, 14 and 21 days of exposure, respectively. At the concentration of $3 \mu \mathrm{M}$, the decrease was only $16 \%$ even after 21-day exposure. Moreover, $3 \mathrm{i}-1000$ at 3-10 $\mu \mathrm{M}$ concentrations had no effect on doxorubicin-induced reductions in hiPSC-CM viability.

\section{Effects of doxorubicin and 3i-1000 on DNA content and GATA4 levels in hiPSC-CMs}

DAPI is a fluorescent dye that binds to A-T rich sequences of double-stranded DNA, thus the fluorescence depends on the amount of the DNA in the cells (Kapuscinski 1995). To evaluate the effect of doxorubicin and 3i-1000 on DNA content in hiPSC-CMs as well as hiPSC-CM density in culture, DAPI staining and HCA were utilized. Over long-term exposure, both doxorubicin and 3i-1000 decreased hiPSCCM density in culture (Fig. 2a). After a 4-day exposure, doxorubicin-induced reduction in cell density was $12 \%$ compared to control, and after a 14-day exposure $49 \%$. Additionally, a 14-day exposure to $10 \mu \mathrm{M} 3 \mathrm{i}-1000$ alone caused an $80 \%(P=0.181)$ reduction in hiPSC-CM number compared to control, whereas at the concentration of $3 \mu \mathrm{M}$ the decrease was $36 \%$. A 4-day exposure to $100 \mathrm{nM}$ doxorubicin decreased the average total intensity of DNA staining by $18 \%(P<0.001)$ compared to control and after 14-day exposure this reduction was $28 \%(P=0.003$; Fig. $2 b)$. We also measured variation in DNA staining intensity as an indication of DNA fragmentation leading to distribution of DNA fragments around nuclei (Darzynkiewicz et al. 2010; Doan-Xuan et al. 2013). Doxorubicin decreased the intranuclear variability of DNA staining intensity by $31 \%(P$ $<0.001), 37 \%(P<0.001)$ and $44 \%(P=0.009)$ after 4,7 and 14-day exposures, respectively (Supplementary Fig. S1). The compound 3i-1000 had no significant effect on the total intensity of DNA staining or the intranuclear variability, either alone or in combination with doxorubicin. To elucidate the effect of doxorubicin and 3i-1000 on GATA4 levels in hiPSC-CMs, average GATA4 staining intensity in nucleus was analysed using HCA (Fig. 2c). Neither doxorubicin nor 3i-1000 had statistically significant effect on nuclear GATA4 staining even after a 14-day exposure.

\section{Effects of doxorubicin and $3 \mathrm{i}-1000$ on proBNP expression in hiPSC-CMs}

BNP is used for the diagnosis of heart failure and cardiac dysfunction (de Lemos et al. 2003; Ruskoaho 2003) 
a

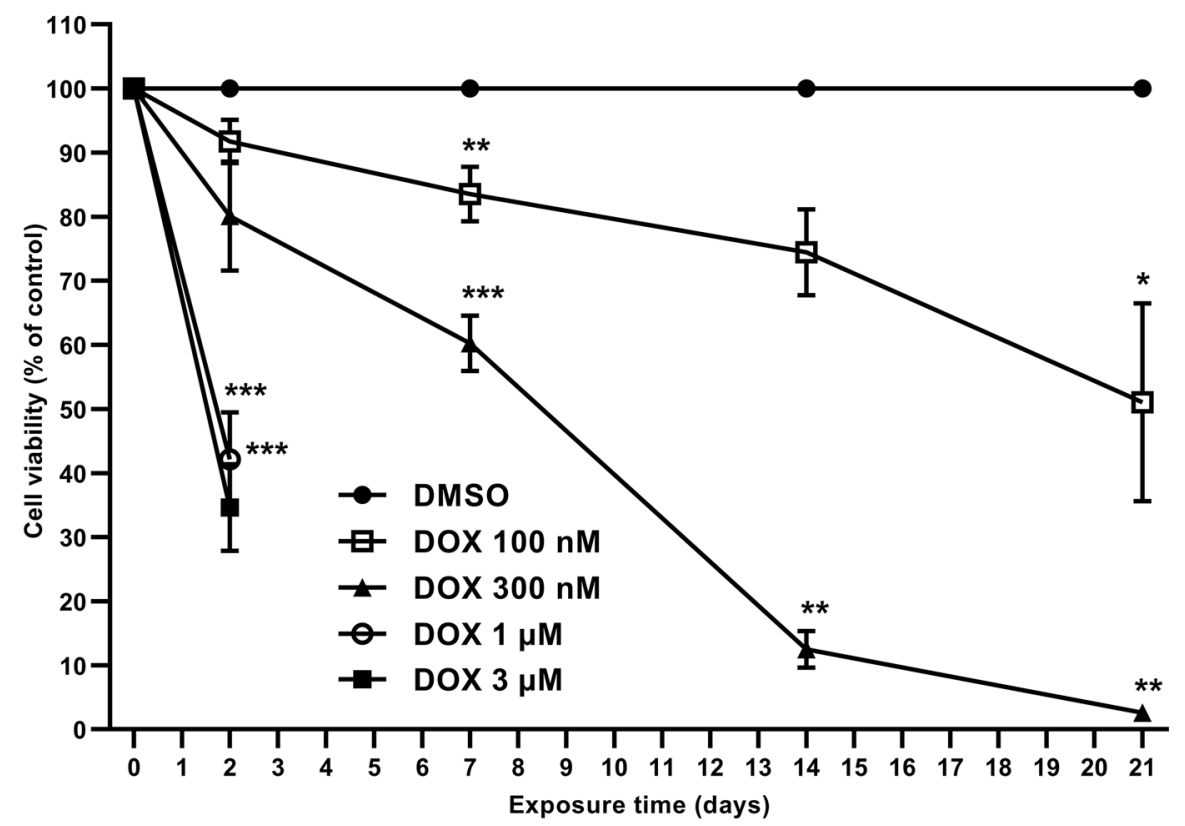

b

7-day exposure

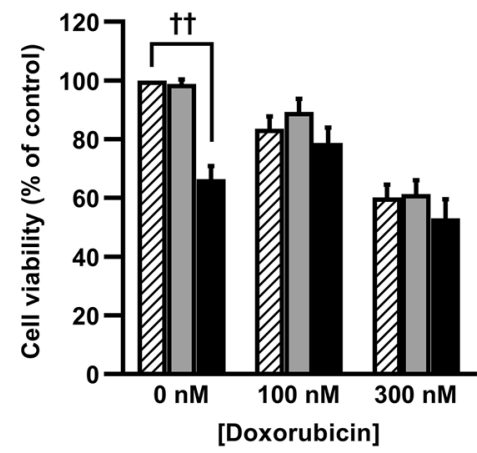

14-day exposure

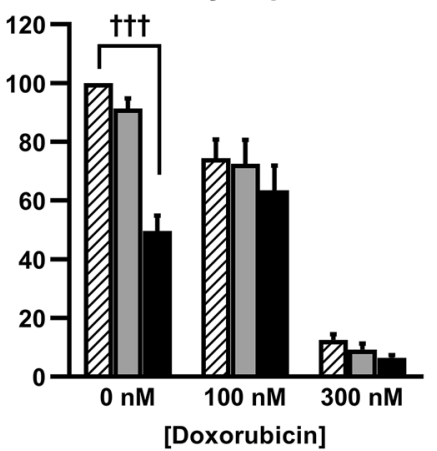

21-day exposure

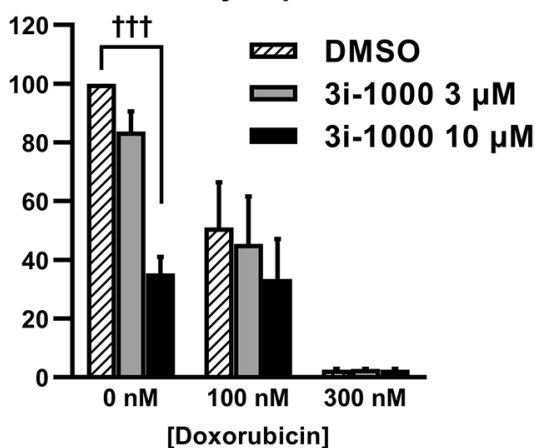

Fig. 1 The effect of long-term doxorubicin (DOX) exposure on the viability of human induced pluripotent stem cell-derived cardiomyocytes (hiPSC-CMs). To study cell viability, the cells were exposed to DOX for 2-21 days after which the MTT assay was performed. a Cell viability after DOX treatment expressed as mean $\pm \operatorname{SEM}(n=4)$. b Cell viability after co-exposure to DOX and $3 \mathrm{i}-1000$ expressed as mean + SEM $(n=4)$. $* * * P<0.001$ vs. DMSO; $* * P<0.01$ vs. DMSO; $* P<0.05$ vs. DMSO; ${ }^{\dagger \dagger} P<0.001$ vs. control; ${ }^{\dagger \dagger} P<0.01$ vs. control (randomized block ANOVA followed by Tukey's HSD)

Fig. S2). When the hiPSC-CMs were exposed simultaneously to $100 \mathrm{nM}$ doxorubicin and $10 \mu \mathrm{M} 3 \mathrm{i}-1000$ for 4 days, the percentage of proBNP ${ }^{+}$cells decreased $60 \%$ $(P<0.001)$. Correspondingly, at the $3 \mu \mathrm{M}$ concentration of $3 \mathrm{i}-1000$, the decrease was $20 \%$. On the other hand, percentage of proBNP + cells was similar in doxorubicin and doxorubicin plus $3 \mathrm{i}-1000$ treated groups at day 7 , as well as in doxorubicin and doxorubicin plus $3 \mu \mathrm{M} 3 \mathrm{i}-1000$ groups at day 14. However, when the cells were exposed simultaneously to doxorubicin (100 nM) and $10 \mu \mathrm{M} 3 \mathrm{i}-1000$ for 14 days, the percentage of proBNP cells increased 19.3fold compared to a 7.7-fold increase in cells exposed to $100 \mathrm{nM}$ doxorubicin only (Fig. 3b). 
a

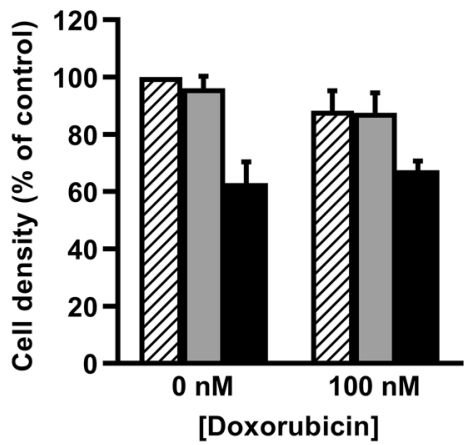

b

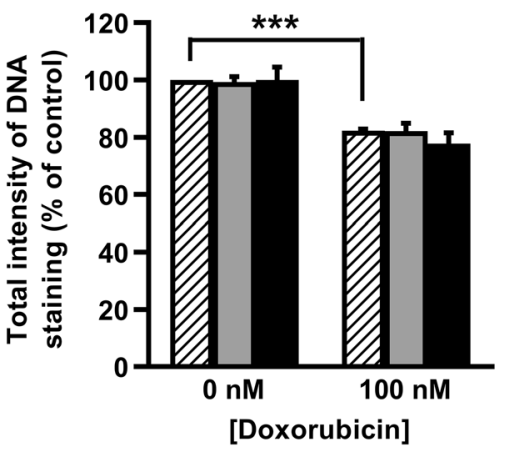

C

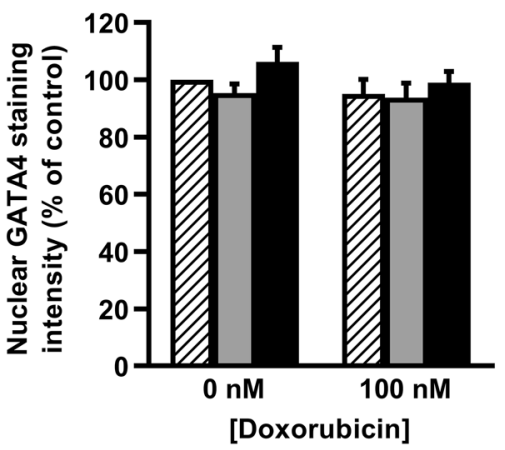

7-day exposure

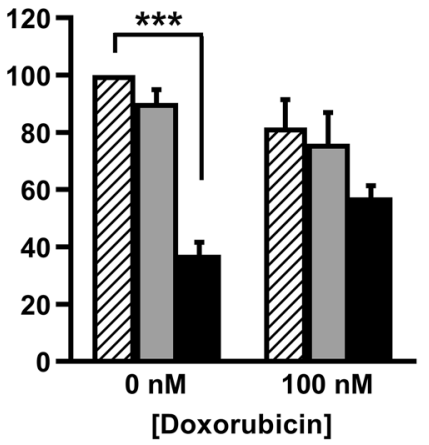

7-day exposure

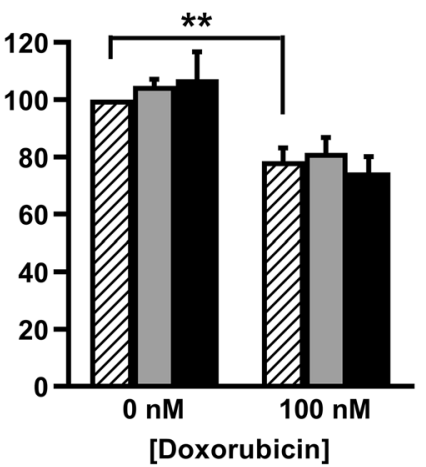

7-day exposure

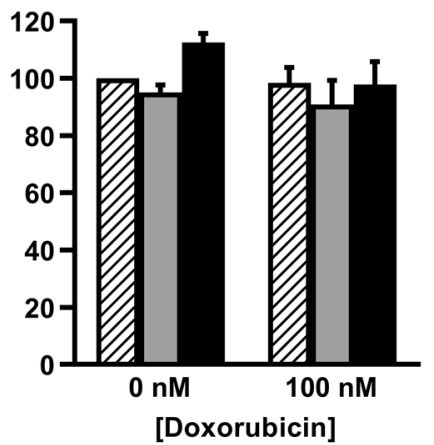

14-day exposure

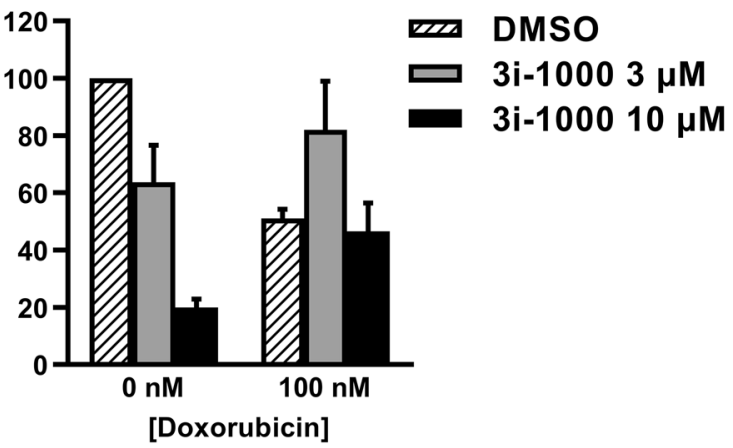

14-day exposure

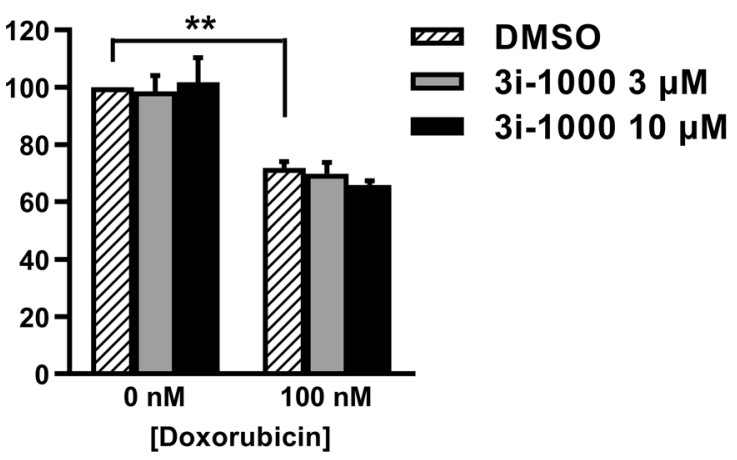

14-day exposure

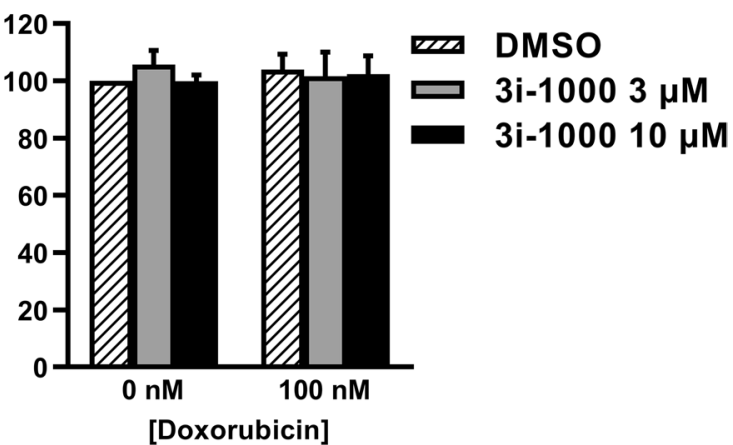

Fig. 2 The effects of doxorubicin and 3i-1000 on DNA content and GATA4 levels in human induced pluripotent stem cell-derived cardiomyocytes (hiPSC-CMs) after long-term exposure. For high-content analysis, the cells were exposed simultaneously to $100 \mathrm{nM}$ doxorubicin and $3 \mathrm{i}-1000$ for 4,7 or 14 days after which they were fixed and stained. Imaging and analysis was carried out using CellInsight

\section{Effects of doxorubicin and $3 \mathrm{i}-1000$ on caspase activation in hiPSC-CMs}

To investigate the effect of doxorubicin and 3i-1000 on cell death, caspase activation was analysed using HCA. Doxorubicin at $100 \mathrm{nM}$ concentration had no effect on the percentage of hiPSC-CMs positive for the fluorescent caspase-3/7 activity reporter after a 4-day exposure, but tended
High-Content Screening Platform. a Cell density. b Intensity of DNA staining. c Intensity of GATA4 staining in nucleus. The results are expressed as mean + SEM $(n=3-5)$. $* * * P<0.001$ vs. control; **P $<0.01$ vs. control (randomized block ANOVA followed by Tukey's HSD)

to increase after a 7-day exposure and produced a significant 3.1-fold increase $(P=0.001)$ in the percentage of cells with active caspase-3/7 after a 14-day exposure (Fig. 3d). The compound $3 \mathrm{i}-1000$ alone at $10 \mu \mathrm{M}$ concentration caused a 5.0 -fold increase $(P=0.007)$ in cells positive for the caspase reporter after a 4-day exposure (Fig. 3c, d). Caspase-3/7 activity was significantly increased also after 7-day (2.5fold, $P=0.007$ ) and 14-day (2.9-fold, $P=0.003$ ) exposures 
to $10 \mu \mathrm{M} 3 \mathrm{i}-1000$. At the $3 \mu \mathrm{M}$ concentration of $3 \mathrm{i}-1000$, the increase was 1.8-fold compared to control at day 14. Interestingly, when the cells were exposed to $10 \mu \mathrm{M} 3 \mathrm{i}-1000$ simultaneously with doxorubicin, the increases were only 1.7 -fold, 1.1-fold and 1.9-fold (not statistically significant) compared to control at days 4, 7 and 14, respectively, indicating cardiomyocyte protective effect for 3i-1000 in hiPSC-CMs.

\section{hiPSC-CMs are more resistant to doxorubicin toxicity than primary cardiomyocytes}

To compare different cardiomyocyte types, hiPSC-CMs and NRVMs were exposed short-term to doxorubicin and 3i-1000 treatments. Short-term exposures were used because NRVMS, unlike hiPSC-CMs, cannot be cultured extended periods of time. In the MTT assay, a 48-h exposure to doxorubicin at $1 \mu \mathrm{M}$ and $3 \mu \mathrm{M}$ concentrations induced $>58 \%$ reductions $(P<0.001)$ in hiPSC-CM viability (Fig. 4a), whereas viability of NRVMs decreased by $>79 \%(P$ $<0.001$; Fig. 4b) (Supplementary Fig. S3 shows IC $_{50}$ values for doxorubicin in both cell types). A 48-h exposure to $100 \mathrm{nM}$ doxorubicin had no substantial effect on the viability of either cardiomyocyte type, while $300 \mathrm{nM}$ doxorubicin decreased the viabilities of both cell types by $20 \%$. The compound $3 \mathrm{i}-1000$ (at $10 \mu \mathrm{M}$ and $30 \mu \mathrm{M}$ concentrations) alone or in the presence of $100 \mathrm{nM}$ doxorubicin tended to increase the viabilities of both cell types (approximately 20\%).

Based on HCA results (Fig. 5), a 24-h exposure to $100 \mathrm{nM}$ doxorubicin induced a $14 \%$ decrease $(P=0.039)$ in the average intensity of GATA4 staining in NRVM nuclei, but not in hiPSC-CMs. Also, 3i-1000 decreased nuclear GATA4 staining intensity in NRVMs by $15 \%(P=0.030)$. Moreover, a 24-h exposure to $100 \mathrm{nM}$ doxorubicin had no effect on the percentage of cardiomyocytes positive for the fluorescent caspase-3/7 activity reporter in either cell type. However, a 24-h exposure to $10 \mu \mathrm{M} 3 \mathrm{i}-1000$ by itself induced a 2.5 fold non-significant increase in hiPSC-CMs and a 1.4-fold significant increase $(P=0.037)$ in NRVMs positive for the caspase reporter compared to DMSO, but not in the presence of $100 \mathrm{nM}$ doxorubicin. It is also notable that in NRVM cultures the basal level of caspase + cardiomyocytes after 24-h exposure to $0.1 \%$ DMSO (on day 3 after cell isolation) was $8 \%$, whereas in hiPSC-CM cultures the basal level of caspase $^{+}$cells was no more than $1 \%$.

\section{In vivo model of chronic doxorubicin toxicity}

As the compound 3i-1000 showed cardioprotective effects in hiPSC-CMs in vitro, we next examined its effects on doxorubicin-induced cardiotoxicity in vivo. First, we carefully tested several rat and mice models (single 15 or $20 \mathrm{mg} / \mathrm{kg}$ dose of doxorubicin), as described in previous
GATA4 in vivo cardioprotection studies (Kobayashi et al. 2006) and in various other studies in which doxorubicin has been shown to affect GATA4 levels (Aries et al. 2004; Bien et al. 2007; Esaki et al. 2008; Koka et al. 2010; Riad et al. 2008). However, under our experimental conditions, using high bolus dose of $15 \mathrm{mg} / \mathrm{kg}$ or $7.5 \mathrm{mg} / \mathrm{kg} /$ week three times i.p. had no effect on LV ejection fraction, instead doxorubicin induced acute diarrhoea and ascites, and serious weight loss (18-20\%) was observed after 7 days in $2 / 3$ of the rats. In our subsequent studies, we finally observed that the model developed for rats by Hayward and Hydock (2007), in which doxorubicin was administered at the dose of $1 \mathrm{mg} / \mathrm{kg} /$ day for 10 days (Fig. 6a), possessed many classical signs of doxorubicininduced late-onset dilated cardiomyopathy, reflected as the decline in both LV ejection fraction and fractional shortening (Fig. 6b, c). Cardiac function was studied by echocardiography at 2, 7, 9, and 11 weeks (Fig. 6b, c). The cardiomyopathy as consequence of doxorubicin treatment started to develop after 7 weeks. At week 9, the LV ejection fraction in the saline group was $68.8 \pm 3.4 \%(n=3)$ and DOX group $55.9 \pm 3.8 \%(n=6)(P=0.044)$, and also $\mathrm{LV}$ fractional shortening was lower in DOX-treated animals. After week 9, the survival of DOX-treated animals decreased quickly (Fig. 6d).

\section{Compound $3 \mathrm{i}-1000$ restores cardiac function in doxorubicin-treated animals}

To study the effect of 3i-1000 on doxorubicin-induced cardiotoxicity in vivo, heart failure was first induced with doxorubicin treatment as described in Fig. 6a, and the compound 3i-1000 (or equal volume of vehicle) was injected i.p. at $30 \mathrm{mg} / \mathrm{kg} / \mathrm{day}$ (the daily dose was divided in two portions) for 2 weeks during the weeks 8 and 9 . Cardiac function was assessed by echocardiography at weeks 2, 7 and 9 (Supplementary Table S1). Interestingly, treatment with compound 3i-1000 significantly inhibited doxorubicin-induced cardiotoxicity by restoring the left ventricular EF (DOX plus 3i-1000 63.8 $\pm 2.6 \%$ vs. DOX $56.8 \pm 1.8 \%, P=0.041$ ) and FS (DOX plus 3i-1000 $36.4 \pm 2.1 \%$ vs. DOX $31.2 \pm 1.3 \%, P=0.043$ ) (Fig. 7a, b). There was no changes in left ventricular posterior wall thickness (LVPW) or internal dimension (LVID) (Fig. 7c, d). Doxorubicin-induced cardiac damage was associated with elevation of ANP and BNP mRNA expression and these increases in gene expressions were not significantly influenced by $3 \mathrm{i}-1000$ treatment (Fig. 7e, f). We did not detect any significant changes on GATA4 protein levels by western blot analysis, but compound 3i-1000 inhibited the doxorubicin-induced decrease in phosphorylated-p38 protein levels (Supplementary Fig. S4). 

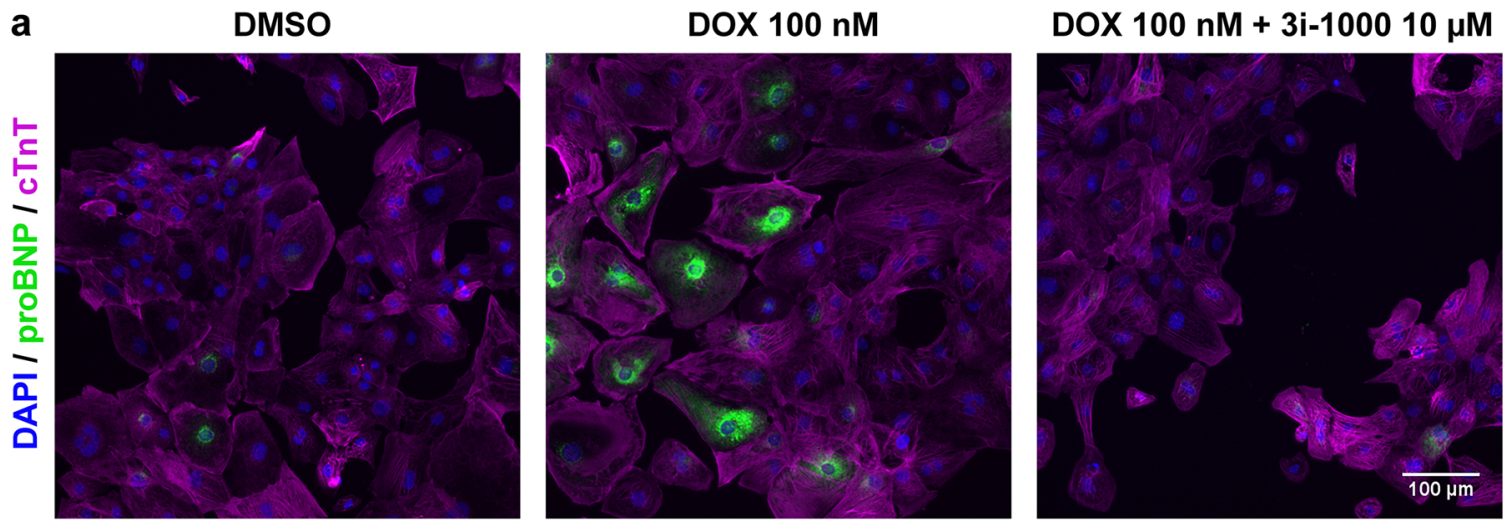

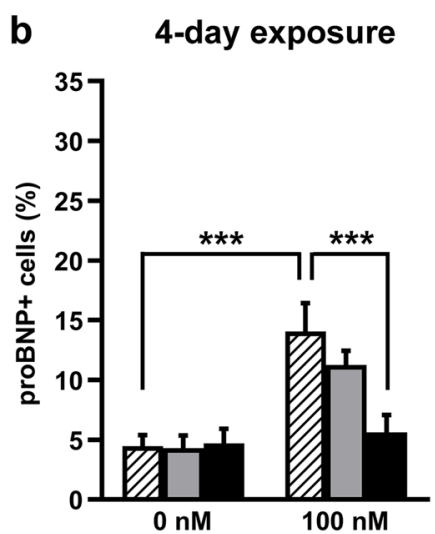

[Doxorubicin]
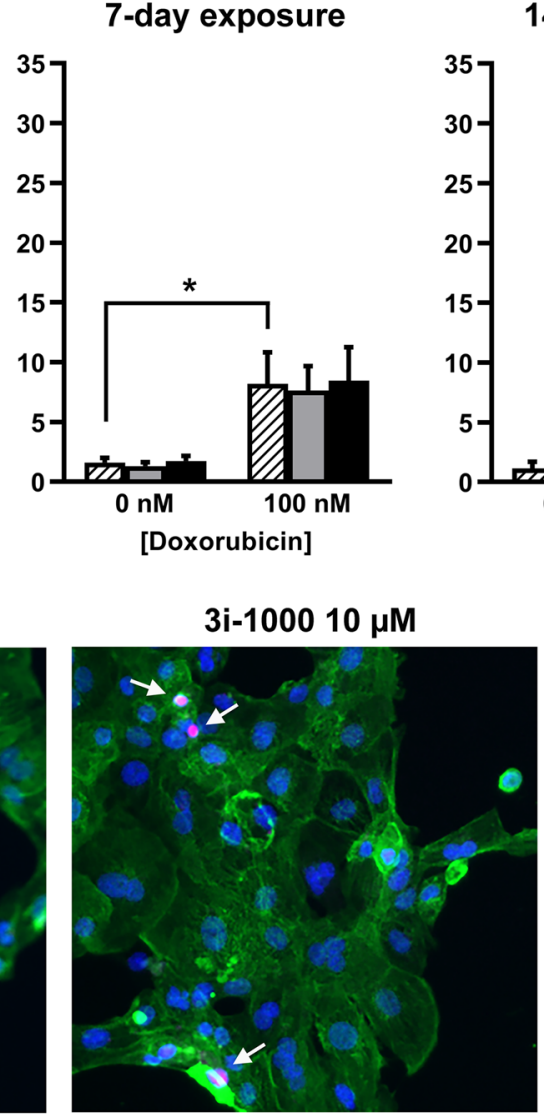

7-day exposure 14-day exposure

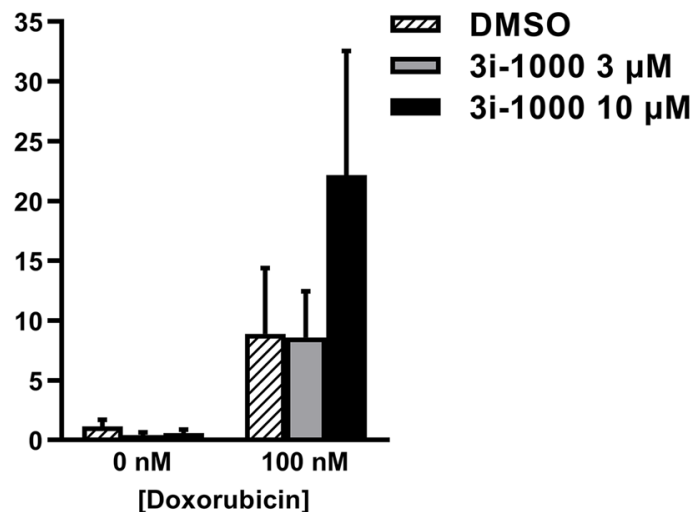

DOX 100 nM + 3i-1000 $10 \mu M$

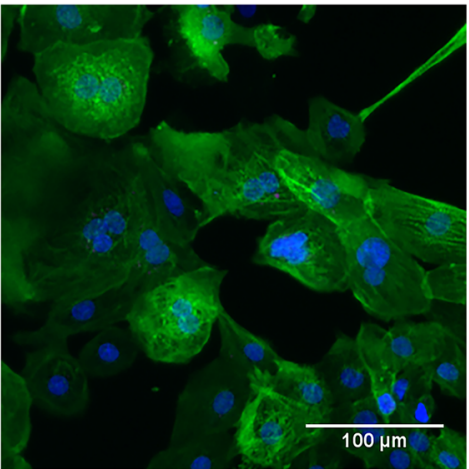

d

4-day exposure

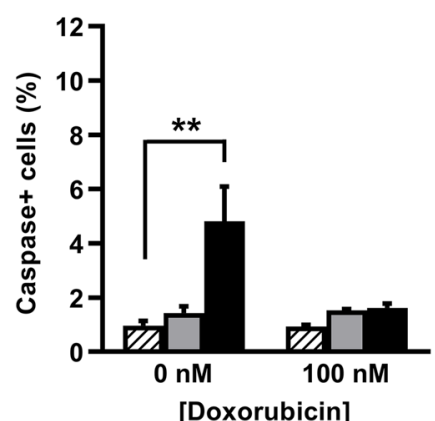

[Doxorubicin]

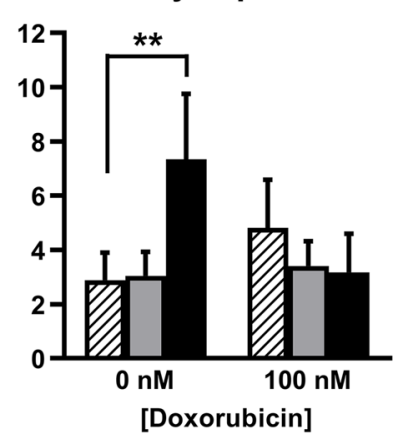

[Doxorubicin]

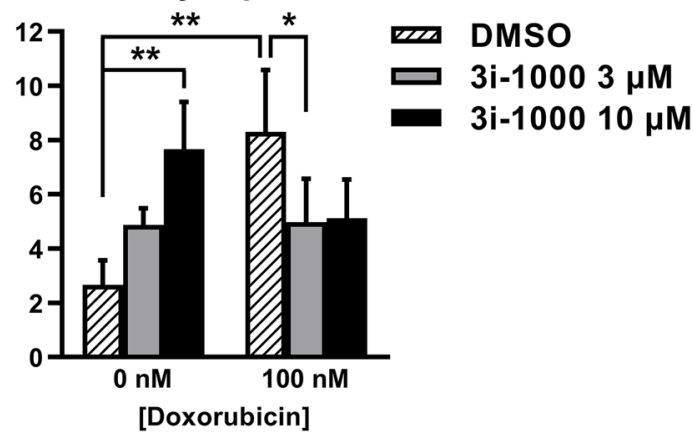


4Fig. 3 The effects of doxorubicin (DOX) and 3i-1000 on expression of pro-B-type natriuretic peptide (proBNP) and caspase activation in human induced pluripotent stem cell-derived cardiomyocytes (hiPSC$\mathrm{CMs}$ ) after long-term exposure. For high-content analysis, the cells were exposed simultaneously to $100 \mathrm{nM}$ DOX and $3 \mathrm{i}-1000$ for 4,7 or 14 days after which they were fixed and stained. Imaging and analysis was carried out using CellInsight High-Content Screening Platform. a Representative images of proBNP staining after a 4-day exposure. b Proportion of proBNP positive hiPSC-CMs. $\mathbf{c}$ Representative images of caspase staining after a 4-day exposure. d Proportion of hiPSCCMs positive for fluorescent caspase-3/7 activity reporter. Adjustments of individual colour channels to enhance brightness and contrast were made identically to all representative images. The results are expressed as mean + SEM $(n=3-4)$. ${ }^{* * *} P<0.001$ vs. control; $* * P<0.01$ vs. control; ${ }^{*} P<0.05$ vs. control (randomized block ANOVA followed by Tukey's HSD). $c$ TnT cardiac troponin T (colour figure online)

\section{Discussion}

Doxorubicin is a widely used chemotherapeutic agent but its clinical applications are limited by dose-dependent cardiotoxicity. Here, we have developed an in vitro model of long-term low-dose administration of doxorubicin utilizing hiPSC-CMs to more accurately mimic long-term doxorubicin dosing and late effects of cardiotoxicity in clinical practice. We exposed hiPSC-CMs to $100 \mathrm{nM}$ doxorubicin for up to 21 days, which differs from the other hiPSC-CM-based models that have recently been used to study doxorubicin toxicity (Burridge et al. 2016; Chaudhari et al. 2016a, b; Louisse et al. 2017; Zhao and Zhang 2017). The concentration of doxorubicin was lower and the exposure time longer, which can be expected to more accurately model chronic dosing in human cancer patients and the cardiotoxicity that ensues. At the same time, it should be taken into account that extended exposure times with repeated medium changes may cause doxorubicin accumulation in the nuclei and associated cardiotoxicity (Kawai et al. 1997). The $100 \mathrm{nM}$ concentration was chosen based on cell viability data evaluation. Micromolar concentrations of doxorubicin caused severe acute toxicity leading to considerable cell death already after 2 days. This acute toxicity was even more severe in NRVMs compared to hiPSC-CMs. Doxorubicin at $100 \mathrm{nM}$ concentration, however, reduced cell viability over long-term exposure without causing excessive cell death. This model also allows the evaluation of efficacy of novel cardioprotective or restorative therapies on chronic cardiomyocyte toxicity in vitro.

Doxorubicin can intercalate with DNA, directly affecting transcription and replication, and leading to apoptosis of cancer cells (Yang et al. 2014). Doxorubicin-induced DNA damage and apoptosis contribute also to its cardiotoxicity (Arola et al. 2000; Lyu et al. 2007; Rochette et al. 2015; Zhang et al. 2012). Here we show that doxorubicininduced decreases in cell number and viability and DNA content were associated with increased caspase-3/7 activity in the chronic in vitro cardiotoxicity model, confirming that caspase-dependent apoptosis contributed to cardiomyocyte death and thus cardiotoxicity. These findings further validate long-term low-dose exposure of hiPSC-CMs as a novel model of doxorubicin-induced cardiotoxicity.

To investigate doxorubicin cardiotoxicity in vivo, we subjected rats to a once a day regimen of doxorubicin for a period of 10 days and then followed up animals for 11 weeks. In previous studies of doxorubicin-induced cardiotoxicity, various animal models, doses and dosing regimens have been used (Aston et al. 2017). Here, our aim was to study the effect of the compound on cardiac function, and therefore, an animal model of doxorubicin-induced cardiotoxicity, in which the ejection fraction decreases, was necessary. The onset of cardiotoxicity was assessed by means of echocardiographic evaluation of cardiac function and natriuretic peptide measurements, both recommended also in clinical practice as diagnostic tools to detect myocardial toxicity (Zamorano et al. 2016). An important characteristic of the model used herein was the use of low doses of doxorubicin that resulted in delayed development of cardiac dysfunction, as shown by significant decrease in LV ejection fraction and fractional shortening only after week 7 . This is in contrast to models that administered single or high doses of doxorubicin that rapidly damage the heart (Hayward and Hydock 2007). The dose of doxorubicin used here, however, was sufficient to activate left ventricular ANP and BNP gene expression, which is consistent with previous reports showing their expression to increase in response to cellular stress (Kinnunen et al. 1992, 1993; Ogawa et al. 1991; Toth et al. 1994). Regarding the clinical value, it is also noteworthy to point out that the studies with single high bolus dose of doxorubicin have been questioned, since they simulate acute cardiotoxicity (Corremans et al. 2019; Gianni et al. 2008). Therefore, a more relevant experimental design for the doxorubicin-induced cardiotoxicity would be the lowdose and repeated administrations, as this is used in clinics (Vejpongsa and Yeh 2014).

Regarding the translational value, it is important to compare also the doxorubicin dose used in the present experiments to the doses used in humans. In clinical use, doxorubicin is administered at the doses of $40-90 \mathrm{mg} /$ $\mathrm{m}^{2}$ as at least 15 min-long intravenous infusions every third week (Vejpongsa and Yeh 2014). For paediatric patients and together with other chemotherapeutics lower doses are used. When a single dose of $12 \mathrm{mg} / \mathrm{kg}$ i.p. was administered to mice, doxorubicin plasma concentration was $60 \mathrm{ng} / \mathrm{ml}$ after $2 \mathrm{~h}$ and $20 \mathrm{ng} / \mathrm{ml}$ after $24 \mathrm{~h}$ (Johansen 1981). Correspondingly, in humans, $60 \mathrm{mg} / \mathrm{m}^{2}$ dose i.v. resulted doxorubicin plasma concentrations $480 \mathrm{ng} / \mathrm{ml}$ after $1 \mathrm{~h}$ and $40 \mathrm{ng} / \mathrm{ml}$ after $24 \mathrm{~h}$ (Barpe et al. 2010). Thus, in the present model in rats, the total cumulative dose of $10 \mathrm{mg} / \mathrm{kg}$ over 10 days roughly resembles a subchronic cardiotoxicity model. On the other hand, the cumulative 


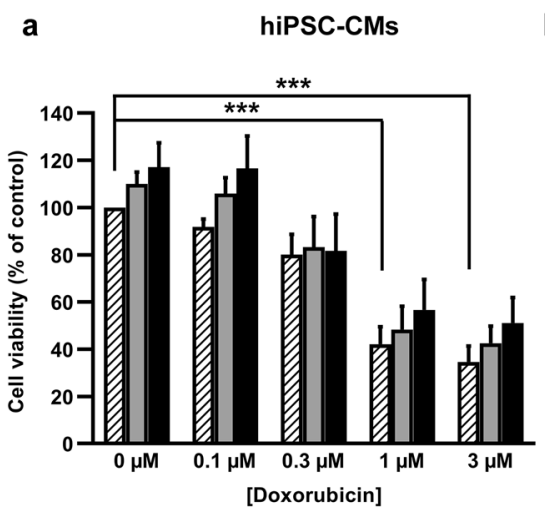

Fig. 4 The effect of short-term doxorubicin exposure on the viability of human induced pluripotent stem cell-derived cardiomyocytes (hiPSC-CMs) and neonatal rat ventricular myocytes (NRVMs). To study cell viability, a hiPSC-CMs and b NRVMs were exposed

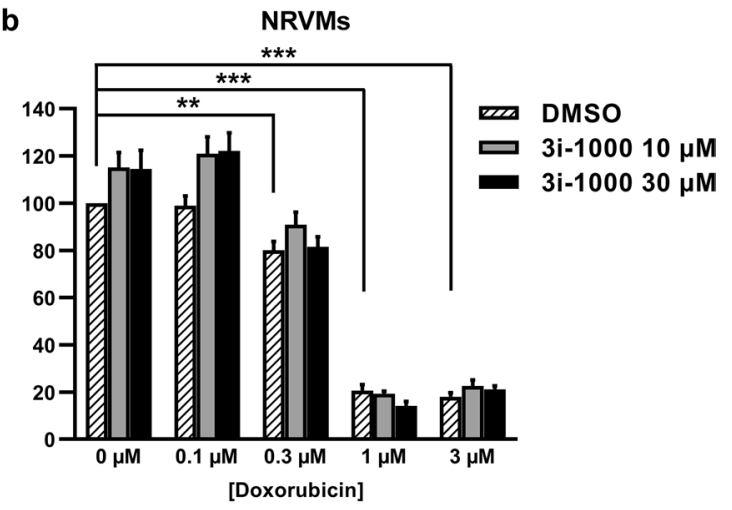

simultaneously to doxorubicin and $3 \mathrm{i}-1000$ for $48 \mathrm{~h}$ after which the MTT assay was performed. The results are expressed as mean + SEM $(n=3-4)$. ${ }^{* * *} P<0.001$ vs. control; $* * P<0.01$ vs. control (randomized block ANOVA followed by Tukey's HSD)

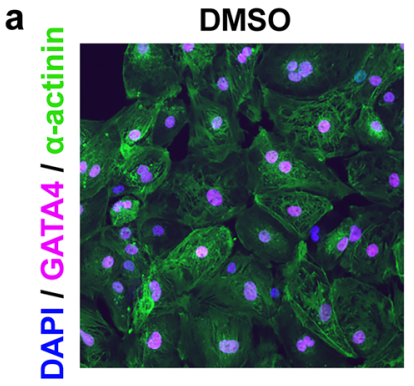

C

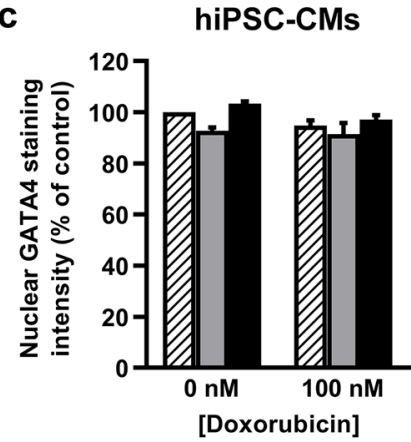

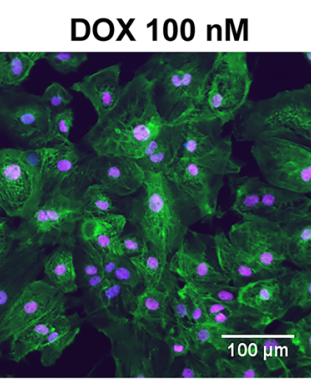

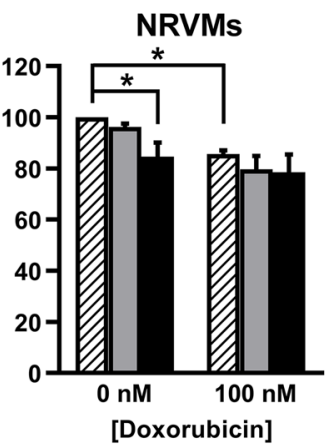

b

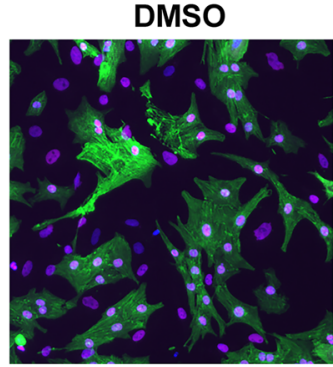

d

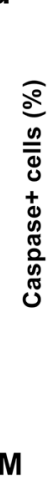

DOX $100 \mathrm{nM}$

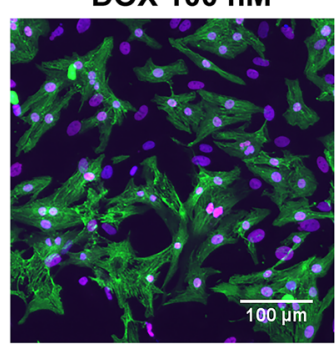

NRVMs

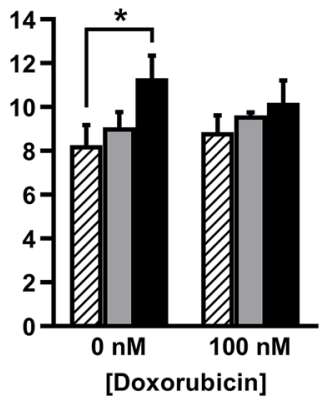

DMSO

Fig. 5 The effects of doxorubicin (DOX) and 3i-1000 on GATA4 levels and caspase activation in human induced pluripotent stem cell-derived cardiomyocytes (hiPSC-CMs) and neonatal rat ventricular myocytes (NRVMs) after short-term exposure. For high-content analysis, the cells were exposed simultaneously to $100 \mathrm{nM}$ DOX and $3 \mathrm{i}-1000$ for $24 \mathrm{~h}$ after which they were fixed and stained. Imaging and analysis was carried out using CellInsight High-Content Screening Platform. Representative images of GATA4 staining in a hiPSC-

dose $10 \mathrm{mg} / \mathrm{kg}$ in rats has been estimated to correspond to $400 \mathrm{mg} / \mathrm{m}^{2}$ in humans $(80 \mathrm{~kg}, 183 \mathrm{~cm}$ ) (Hayward and Hydock 2007). Moreover, in vitro concentrations 3 and $1 \mu \mathrm{M}$ compare to the initial plasma levels of doxorubicin
CMs and b primary NRVM cultures. $\mathbf{c}$ Average intensity of nuclear GATA4 staining. d Proportion of cardiomyocytes positive for fluorescent caspase-3/7 activity reporter. Adjustments of individual colour channels to enhance brightness and contrast were made identically to all representative images. The results are expressed as mean + SEM $(n=3-4)$. ${ }^{*} P<0.05$ vs. control (randomized block ANOVA followed by Tukey's HSD) (colour figure online)

detected in patients after a bolus administration, whereas concentrations of 300 and $100 \mathrm{nM}$ compare to the plasma levels that are reached within few hours after doxorubicin administration and are maintained by continuous infusion 
a

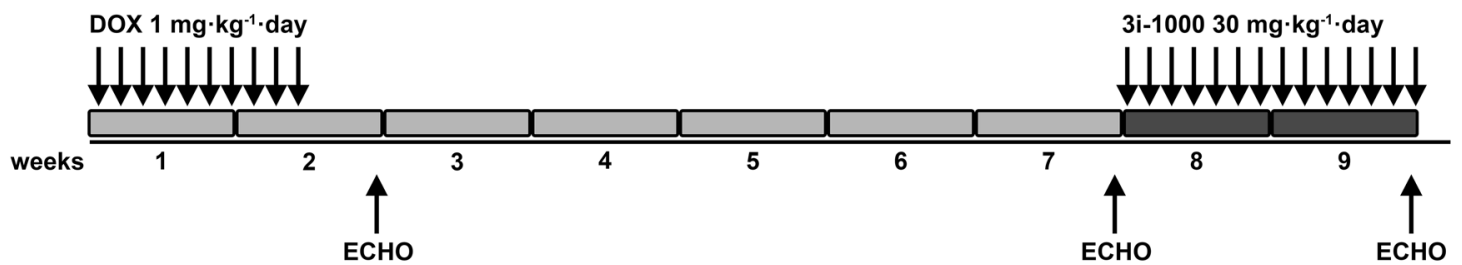

b

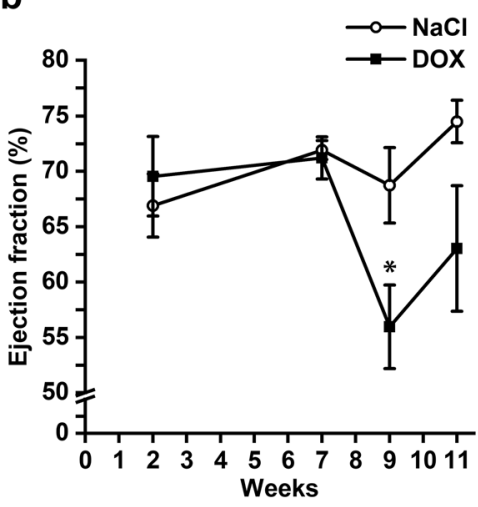

C

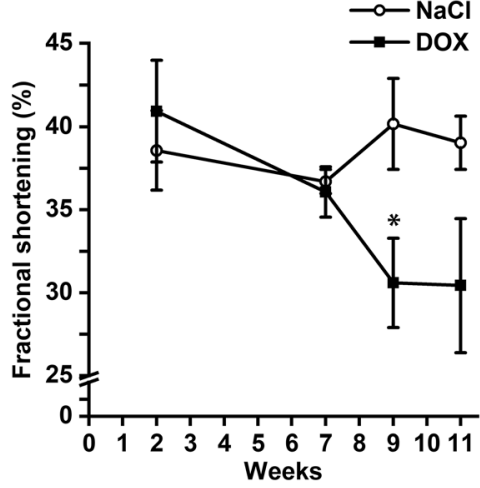

d

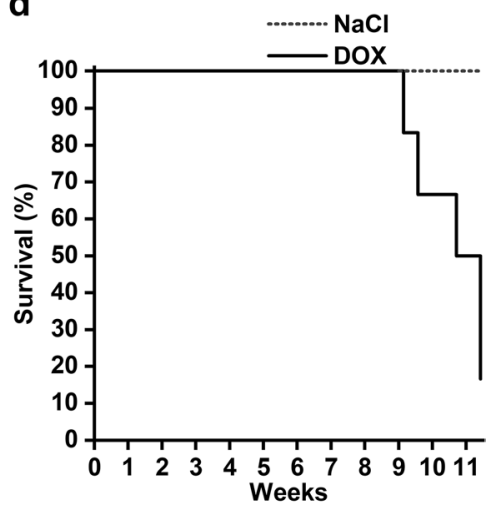

Fig. 6 The in vivo animal model of doxorubicin (DOX) cardiotoxicity. The rats received saline or DOX $1 \mathrm{mg} / \mathrm{kg} /$ day for 10 days and were followed up to 11 weeks. a The experimental design of chronic DOX cardiotoxicity in rats. DOX was administered $1 \mathrm{mg} / \mathrm{kg} /$ day i.p. for 10 days. b, c Cardiac function was measured by echocardiography at 2, 7, 9 and 11 weeks. $\mathbf{d}$ The survival of the DOX-treated

(Creasey et al. 1976; Greene et al. 1983; Muller et al. 1993; Speth et al. 1987).

Using these in vitro and in vivo models, we studied whether the GATA4-targeted compound 3i-1000 has cardioprotective effects on doxorubicin-induced cardiotoxicity. GATA4 is a member of the GATA family of zinc finger transcription factor, which was originally discovered as a regulator of cardiac development and subsequently identified as a major regulator of cardiac hypertrophy and cell survival (Pikkarainen et al. 2004; Suzuki 2011; Tremblay et al. 2018). Several hypertrophic stimuli directly regulate GATA4 DNA-binding and transcriptional activity in vitro (Hasegawa et al. 1997; Majalahti et al. 2007; Morimoto et al. 2000; Morisco et al. 2001; Kerkelä et al. 2002) and in vivo (Hautala et al. 2001; Majalahti et al. 2007). Moreover, mechanical stretch transiently increases GATA4 DNA-binding activity and transcript levels followed by increases in the expression of BNP, ANP, and skeletal $\alpha$-actin genes (Pikkarainen et al. 2003). Interestingly, GATA4 overexpression alone induces hypertrophic myocardial cell growth and hypertrophic gene expression in GATA4 transgenic mice (Liang et al. 2001). Similarly, overexpression of GATA4 in cell culture by adenoviral gene transfer induces cardiomyocyte hypertrophy (Liang et al. 2001) and sarcomere reorganization as efficiently as endothelin-1 and phenylephrine (Charron et al. 2001). For stress-induced cardiac hypertrophic response, the rats decreased quickly after 9 weeks. The results are expressed as mean \pm SEM; $* P<0.05$ vs. control (Welch's $t$ test). Number of animals at 2, 7 and 9 week time points: $\mathrm{NaCl}=3$; $\mathrm{DOX}=6$, week 11 time point: $\mathrm{NaCl}=3$; $\mathrm{DOX}=3$. Panels $\mathbf{b}-\mathbf{d}$ show data from animals that were not treated with 3i-1000. ECHO echocardiography

GATA4 phosphorylation of Ser-105 has shown to be necessary (van Berlo et al. 2011).

Recently, we have reported the identification of small molecules that either inhibit or enhance the GATA4NKX2-5 transcriptional synergy (Jumppanen et al. 2019; Välimäki et al. 2017). The most potent inhibitor of GATA4NKX2-5 interaction, 3i-1000, had no influence on the baseline GATA4 proteins levels in NRVMs, whereas the phenylephrine-induced elevation in GATA4 Ser-105 phosphorylation was significantly inhibited by $3 \mathrm{i}-1000$ (Kinnunen et al. 2018). Although the exact mechanisms of action remains to established, the compound 3i-1000 inhibits BNP transcription, and stretch-, endothelin-1- and phenylephrinestimulated gene expression of ANP and BNP, as well as hypertrophic cell growth in cardiomyocytes while having no effect on GATA4 or NKX2-5 DNA binding or on the activity of protein kinases involved in the regulation of GATA4 phosphorylation (Välimäki et al. 2017; Kinnunen et al. 2018). Moreover, enhanced cardiac function in vivo in experimental models of myocardial infarction and hypertension has been observed (Kinnunen et al. 2018). Importantly, in our present experiments, the compound protected from doxorubicin-induced cardiac damage, as reflected by the restoration of LV ejection fraction and fractional shortening in doxorubicin-treated animals. Interestingly, improvement in cardiac function by $3 \mathrm{i}-1000$ was not associated with the 
a

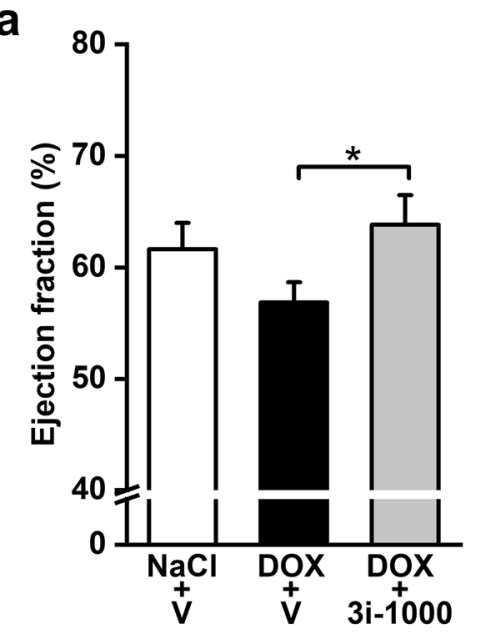

d

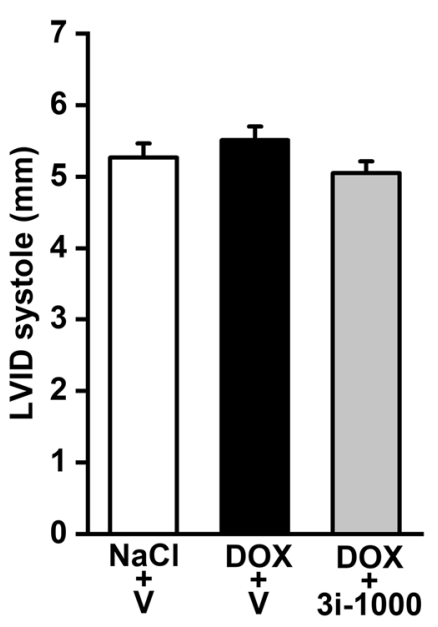

b

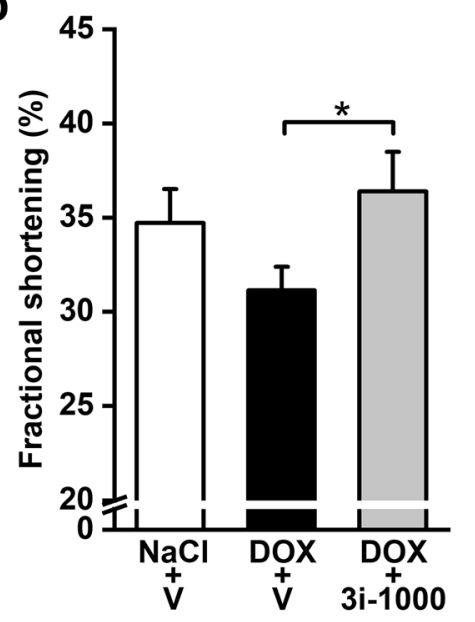

e

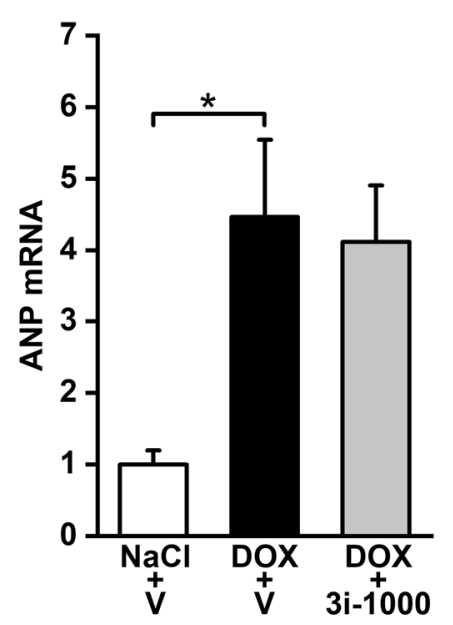

C

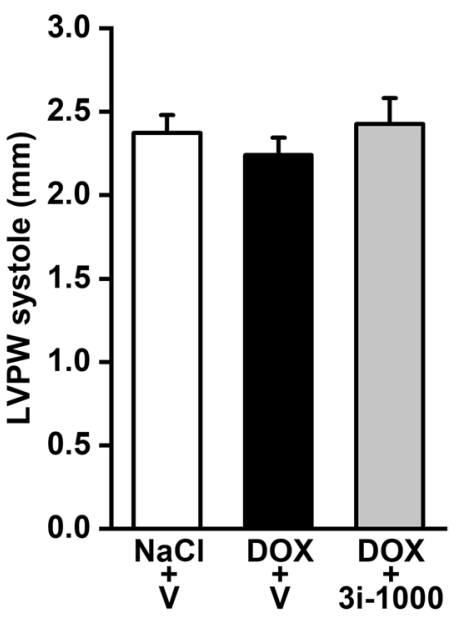

f

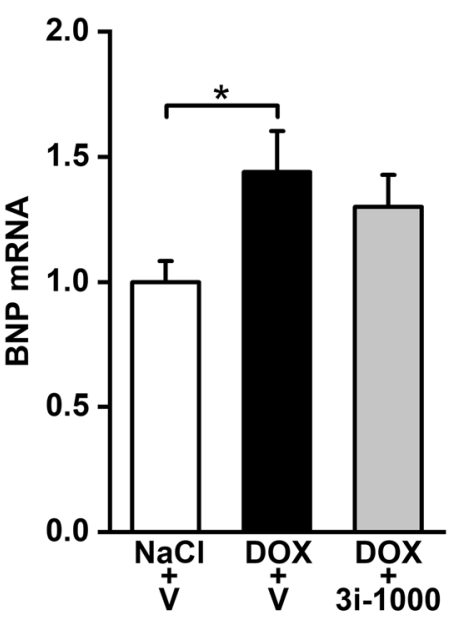

Fig. 7 The effect of 3i-1000 on doxorubicin (DOX) cardiotoxicity in vivo. The rats received saline or DOX $1 \mathrm{mg} / \mathrm{kg} /$ day for 10 days and were then treated with compound $3 \mathrm{i}-100030 \mathrm{mg} / \mathrm{kg} /$ day or DMSO vehicle (V) for 2 weeks (weeks 8 and 9). a-d Left ventricular functional and structural changes measured by echocardiography at the end of the experiments. e, f mRNA extracted from left ventricles and measured by RT-PCR. The levels of transcripts were normalised to ribosomal $18 \mathrm{~S}$ quantified from the same samples. The results are expressed as mean $+\mathrm{SEM}$; $* P<0.05$ (independent-samples $t$ test). Number of animals: $\mathrm{NaCl}+\mathrm{V}=10 ; \mathrm{DOX}+\mathrm{V}=9$ (except for $\mathbf{e}, \mathbf{f}$ $\mathrm{DOX}+\mathrm{V}=8) ; \mathrm{DOX}+3 \mathrm{i}-1000=8 . L V P W$ left ventricular posterior wall thickness, $L V I D$ left ventricular internal dimension decrease in left ventricular ANP and BNP mRNA levels, suggesting a direct effect of doxorubicin on LV natriuretic peptide gene expression.

The compound 3i-1000 showed cardioprotective effects also in vitro. It attenuated doxorubicin-induced increase in proBNP expression in hiPSC-CMs after a 4-day exposure. Moreover, exposure of $3 \mathrm{i}-1000$ at $3 \mu \mathrm{M}$ and $10 \mu \mathrm{M}$ concentrations attenuated doxorubicin-induced increase in caspase activation up to 14 days. The long-term exposures (up to 21 days), however, revealed toxic effects of 3i-1000 in cardiomyocytes. In our previous study (Karhu et al. 2018), the toxicity of eight compounds (3i-1000 and its derivatives) at concentrations ranging from $10 \mathrm{nM}$ to $30 \mu \mathrm{M}$ on the viability of eight different cell types were studied in detail. In these short-term experiments ( $24 \mathrm{~h}$ ), 3i-1000 was non-toxic to cardiomyocytes (NRVMs, hiPSC-CMs), fibroblasts and
H9c2 cardiac myoblasts. Interestingly, stem cells were very sensitive to detect toxicity of $3 i-1000$ and structure-toxicity analysis of all compounds revealed a characteristic dihedral angle in the GATA4-targeted compounds that may cause stem cell toxicity (Karhu et al. 2018).

Overall, our present in vitro results show that the protective effects of 3i-1000 on doxorubicin-induced cardiotoxicity are dependent on dose and treatment time, and also suggest distinct mechanisms of action for doxorubicin- and 3i-1000-induced cardiotoxicities. Doxorubicin had a direct effect on DNA content in cardiomyocytes, leading to caspase activation and apoptosis, whereas compound 3i-1000 had no direct effect on DNA content but increased caspase activity. Moreover, the present results not only show that $3 \mathrm{i}-1000$ protected cardiomyocytes from doxorubicin-induced elevation of proBNP expression but 
also that doxorubicin protected cardiomyocytes from 3i-1000-induced caspase activation. Cell viability data at 7 and 14-day time points show the same effect: exposure to $3 \mathrm{i}-1000$ at $10 \mu \mathrm{M}$ concentration alone decreased hiPSC-CM viability, but this effect was attenuated with co-exposure to $100 \mathrm{nM}$ doxorubicin. Thus, it is possible that targeting GATA4 with 3i-1000 may be detrimental to healthy cardiomyocytes in long-term. On the other hand, when cardiomyocytes are exposed to stressors (e.g. doxorubicin), co-treatment with $3 \mathrm{i}-1000$ has protective effects in cardiomyocytes. Furthermore, together with our previous toxicological analysis of 3i-1000 and its derivatives, the present data supports further development of 3i-1000 derivatives.

Interestingly, in the present study doxorubicin had no effect on GATA4 protein levels either in vivo or in hiPSC-CMs even after long-term exposure. Statistically significant changes in GATA4 levels were detected only in NRVMs after short-term doxorubicin exposure. In previously published in vitro studies, in which doxorubicin was shown to decrease GATA4 mRNA and protein levels, doxorubicin concentrations were higher and exposure times shorter, $\leq 24$ h (Aries et al. 2004, 2014; Kim et al. 2003; Kobayashi et al. 2006, 2010). Similarly, in the prior in vivo studies mice were treated with a single high-dose injection of doxorubicin (Aries et al. 2004; Kobayashi et al. 2006). Therefore, it is possible that the changes in GATA4 levels are related to short-term high-dose doxorubicin treatments. However, interspecies differences both in vitro and in vivo cannot be ruled out. Furthermore, the maturity level of the cells and the potential limitations that may entail should be considered when utilizing hiPSC-CMs. Although more investigations are needed in the future to fully understand the exact mechanisms of action of doxorubicin as well as the GATA4-targeted compound 3i-1000, our current results suggest that their mechanisms of action are not related to obvious changes in GATA4 protein levels.

Regarding preclinical drug development, our results highlight the importance of choosing an appropriate experimental model for compound testing already in early phases of drug discovery projects. The delayed toxicity of GATA4targeted compound 3i-1000 demonstrates the significance of using longer exposure times in in vitro toxicity screening, which is possible when using hiPSC-CMs as these cells can be cultured for significantly longer periods of time compared to primary cardiomyocytes. Utilizing differentiated human cells also eliminates the influence of interspecies differences and helps to reduce the use of experimental animals. Furthermore, choosing a suitable model is a key element also in investigating the mechanism of doxorubicin cardiotoxicity as reflected by the lack of doxorubicin-induced GATA4 protein depletion in response to chronic low-dose treatments in hiPSC-CMs.
In summary, long-term exposure of hiPSC-CMs is a useful in vitro model to investigate the mechanisms of delayed doxorubicin-induced cardiotoxicity and novel cardioprotective therapies. The GATA4-targeted compound 3i-1000 exhibited cardioprotective potential in vitro as well as in vivo. Over chronic exposure the compound was, however, toxic to cardiomyocytes and hence further structural optimization is required to develop non-toxic derivatives.

Acknowledgements Open access funding provided by University of Helsinki including Helsinki University Central Hospital. We thank Marja Arbelius, Jani Aro, Erja Mustonen, and Annika Korvenpää for expert technical assistance. The Biomedicum Imaging Unit (Helsinki Institute of Life Science, University of Helsinki) is acknowledged for providing instrumentation for high-content analysis. The research was funded by Business Finland (3iRegeneration, project 40395/13), the Academy of Finland (project 2666621), the Finnish Foundation for Cardiovascular Research, and the Sigrid Jusélius Foundation.

Author contributions HR, VT and STK designed the in vitro experiments. HR, SMK, MT and MJV designed the in vivo experiments. STK performed the in vitro experiments. SMK and MT performed the in vivo experiments. ZS performed the echocardiography. STK, SMK, MT and ZS analysed the data. STK, SMK, MT, MJV, ZS, VT and HR contributed to the writing of the manuscript. All authors reviewed and accepted the manuscript.

Data availability The datasets generated during and analysed during the current study are available from the corresponding author on reasonable request.

\section{Compliance with ethical standards}

Conflict of interest SMK, MJV and HR are inventors in a patent application "Pharmaceutical compounds" (PCT/FI2017/050661) concerning the compound $3 \mathrm{i}-1000$ and its derivatives. No other competing interests to disclose.

Open Access This article is licensed under a Creative Commons Attribution 4.0 International License, which permits use, sharing, adaptation, distribution and reproduction in any medium or format, as long as you give appropriate credit to the original author(s) and the source, provide a link to the Creative Commons licence, and indicate if changes were made. The images or other third party material in this article are included in the article's Creative Commons licence, unless indicated otherwise in a credit line to the material. If material is not included in the article's Creative Commons licence and your intended use is not permitted by statutory regulation or exceeds the permitted use, you will need to obtain permission directly from the copyright holder. To view a copy of this licence, visit http://creativecommons.org/licenses/by/4.0/.

\section{References}

Aries A, Paradis P, Lefebvre C, Schwartz RJ, Nemer M (2004) Essential role of GATA4 in cell survival and drug-induced cardiotoxicity. Proc Natl Acad Sci USA 101:6975-6980. https://doi. org/10.1073/pnas.0401833101

Aries A, Whitcomb J, Shao W, Komati H, Saleh M, Nemer M (2014) Caspase-1 cleavage of transcription factor GATA4 and 
regulation of cardiac cell fate. Cell Death Dis 5:e1566. https:// doi.org/10.1038/cddis.2014.524

Arola OJ, Saraste A, Pulkki K, Kallajoki M, Parvinen M, Voipio-Pulkki LM (2000) Acute doxorubicin cardiotoxicity involves cardiomyocyte apoptosis. Cancer Res 60:1789-1792

Aston WJ, Hope DE, Nowak AK, Robinson BW, Lake RA, Lesterhuis WJ (2017) A systematic investigation of the maximum tolerated dose of cytotoxic chemotherapy with and without supportive care in mice. BMC Cancer 17:684-017-3677-7. https://doi. org/10.1073/pnas.0401833101

Barpe DR, Rosa DD, Froehlich PE (2010) Pharmacokinetic evaluation of doxorubicin plasma levels in normal and overweight patients with breast cancer and simulation of dose adjustment by different indexes of body mass. Eur J Pharm Sci 41:458-463. https://doi. org/10.1016/j.ejps.2010.07.015

Bien S, Riad A, Ritter CA, Gratz M, Olshausen F, Westermann D, Grube M, Krieg T, Ciecholewski S, Felix SB, Staudt A, Schultheiss HP, Ewert R, Volker U, Tschope C, Kroemer HK (2007) The endothelin receptor blocker bosentan inhibits doxorubicininduced cardiomyopathy. Cancer Res 67:10428-10435. https:// doi.org/10.1158/0008-5472.CAN-07-1344

Bisping E, Ikeda S, Kong SW, Tarnavski O, Bodyak N, McMullen JR, Rajagopal S, Son JK, Ma Q, Springer Z, Kang PM, Izumo S, $\mathrm{Pu}$ WT (2006) GATA4 is required for maintenance of postnatal cardiac function and protection from pressure overload-induced heart failure. Proc Natl Acad Sci USA 103:14471-14476. https ://doi.org/10.1073/pnas.0602543103

Bistola V, Nikolopoulou M, Derventzi A, Kataki A, Sfyras N, Nikou N, Toutouza M, Toutouzas P, Stefanadis C, Konstadoulakis MM (2008) Long-term primary cultures of human adult atrial cardiac myocytes: cell viability, structural properties and BNP secretion in vitro. Int J Cardiol 131:113-122. https://doi.org/10.1016/j. ijcard.2007.10.058

Bruneau BG, Piazza LA, de Bold AJ (1997) BNP gene expression is specifically modulated by stretch and ET-1 in a new model of isolated rat atria. Am J Physiol 273:H2678-H2686. https://doi. org/10.1152/ajpheart.1997.273.6.H2678

Burridge PW, Matsa E, Shukla P, Lin ZC, Churko JM, Ebert AD, Lan F, Diecke S, Huber B, Mordwinkin NM, Plews JR, Abilez OJ, Cui B, Gold JD, Wu JC (2014) Chemically defined generation of human cardiomyocytes. Nat Methods 11:855-860. https:// doi.org/10.1038/nmeth.2999

Burridge PW, Li YF, Matsa E, Wu H, Ong SG, Sharma A, Holmstrom A, Chang AC, Coronado MJ, Ebert AD, Knowles JW, Telli ML, Witteles RM, Blau HM, Bernstein D, Altman RB, Wu JC (2016) Human induced pluripotent stem cell-derived cardiomyocytes recapitulate the predilection of breast cancer patients to doxorubicin-induced cardiotoxicity. Nat Med 22:547-556. https://doi.org/10.1038/nm.4087

Cathala G, Savouret JF, Mendez B, West BL, Karin M, Martial JA, Baxter JD (1983) A method for isolation of intact, translationally active ribonucleic acid. DNA 2:329-335. https://doi. org/10.1089/dna.1983.2.329

Charron F, Tsimiklis G, Arcand M, Robitaille L, Liang Q, Molkentin JD, Meloche S, Nemer M (2001) Tissue-specific GATA factors are transcriptional effectors of the small GTPase RhoA. Genes Dev 15:2702-2719. https://doi.org/10.1101/gad.915701

Chaudhari U, Nemade H, Gaspar JA, Hescheler J, Hengstler JG, Sachinidis A (2016a) MicroRNAs as early toxicity signatures of doxorubicin in human-induced pluripotent stem cell-derived cardiomyocytes. Arch Toxicol 90:3087-3098. https://doi. org/10.1007/s00204-016-1668-0

Chaudhari U, Nemade H, Wagh V, Gaspar JA, Ellis JK, Srinivasan SP, Spitkovski D, Nguemo F, Louisse J, Bremer S, Hescheler J, Keun HC, Hengstler JG, Sachinidis A (2016b) Identification of genomic biomarkers for anthracycline-induced cardiotoxicity in human iPSC-derived cardiomyocytes: an in vitro repeated exposure toxicity approach for safety assessment. Arch Toxicol 90:2763-2777. https://doi.org/10.1007/s00204-015-1623-5

Conway A, McCarthy AL, Lawrence P, Clark RA (2015) The prevention, detection and management of cancer treatment-induced cardiotoxicity: a meta-review. BMC Cancer 15:366. https://doi. org/10.1186/s12885-015-1407-6

Corremans R, Adao R, De Keulenaer GW, Leite-Moreira AF, Bras-Silva C (2019) Update on pathophysiology and preventive strategies of anthracycline-induced cardiotoxicity. Clin Exp Pharmacol Physiol 46:204-215. https://doi. org/10.1111/1440-1681.13036

Creasey WA, McIntosh LS, Brescia T, Odujinrin O, Aspnes GT, Murray E, Marsh JC (1976) Clinical effects and pharmacokinetics of different dosage schedules of adriamycin. Cancer Res $36: 216-221$

Darzynkiewicz Z, Halicka HD, Zhao H (2010) Analysis of cellular DNA content by flow and laser scanning cytometry. Adv Exp Med Biol 676:137-147. https://doi. org/10.1007/978-1-4419-6199-0_9

de Lemos JA, McGuire DK, Drazner MH (2003) B-type natriuretic peptide in cardiovascular disease. Lancet 362:316-322. https:// doi.org/10.1016/S0140-6736(03)13976-1

Doan-Xuan QW, Sarvari AK, Fischer-Posovsky P, Wabitsch M, Balajthy Z, Fesus L, Bacso Z (2013) High content analysis of differentiation and cell death in human adipocytes. Cytom Part A 83:933-943. https://doi.org/10.1002/cyto.a.22333

Esaki M, Takemura G, Kosai K, Takahashi T, Miyata S, Li L, Goto K, Maruyama R, Okada H, Kanamori H, Ogino A, Ushikoshi H, Minatoguchi S, Fujiwara T, Fujiwara H (2008) Treatment with an adenoviral vector encoding hepatocyte growth factor mitigates established cardiac dysfunction in doxorubicin-induced cardiomyopathy. Am J Physiol Heart Circ Physiol 294:H1048-H1057. https://doi.org/10.1152/ajpheart.01102.2007

Ferreira MPA, Ranjan S, Kinnunen S, Correia A, Talman V, Makila E, Barrios-Lopez B, Kemell M, Balasubramanian V, Salonen J, Hirvonen J, Ruskoaho H, Airaksinen AJ, Santos HA (2017) Drugloaded multifunctional nanoparticles targeted to the endocardial layer of the injured heart modulate hypertrophic signaling. Small. https://doi.org/10.1002/smll.201701276

Gianni L, Herman EH, Lipshultz SE, Minotti G, Sarvazyan N, Sawyer DB (2008) Anthracycline cardiotoxicity: from bench to bedside. J Clin Oncol 26:3777-3784. https://doi.org/10.1200/ JCO.2007.14.9401

Greene RF, Collins JM, Jenkins JF, Speyer JL, Myers CE (1983) Plasma pharmacokinetics of adriamycin and adriamycinol: implications for the design of in vitro experiments and treatment protocols. Cancer Res 43:3417-3421

Hasegawa K, Lee SJ, Jobe SM, Markham BE, Kitsis RN (1997) cisActing sequences that mediate induction of $\beta$-myosin heavy chain gene expression during left ventricular hypertrophy due to aortic constriction. Circulation 96:3943-3953. https://doi. org/10.1161/01.cir.96.11.3943

Hautala N, Tokola H, Luodonpaa M, Puhakka J, Romppanen H, Vuolteenaho O, Ruskoaho H (2001) Pressure overload increases GATA4 binding activity via endothelin-1. Circulation 103:730735. https://doi.org/10.1161/01.cir.103.5.730

Hayward R, Hydock DS (2007) Doxorubicin cardiotoxicity in the rat: an in vivo characterization. J Am Assoc Lab Anim Sci 46:20-32

Johansen PB (1981) Doxorubicin pharmacokinetics after intravenous and intraperitoneal administration in the nude mouse. Cancer Chemother Pharmacol 5:267-270. https://doi.org/10.1007/bf004 34396

Jumppanen M, Kinnunen SM, Välimäki MJ, Talman V, Auno S, Bruun T, Boije Af Gennäs G, Xhaard H, Aumuller IB, Ruskoaho H, Yli-Kauhaluoma J (2019) Synthesis, identification, and 
structure-activity relationship analysis of GATA4 and NKX2-5 protein-protein interaction modulators. J Med Chem 62:82848310. https://doi.org/10.1021/acs.jmedchem.9b01086

Jurado Acosta A, Rysä J, Szabo Z, Moilanen AM, Komati H, Nemer M, Ruskoaho H (2017) Transcription factor PEX1 modulates extracellular matrix turnover through regulation of MMP-9 expression. Cell Tissue Res 367:369-385. https://doi.org/10.1007/s0044 $1-016-2527-2$

Kapuscinski J (1995) DAPI: a DNA-specific fluorescent probe. Biotech Histochem 70:220-233

Karhu ST, Välimäki MJ, Jumppanen M, Kinnunen SM, Pohjolainen L, Leigh RS, Auno S, Foldes G, Boije Af Gennäs G, Yli-Kauhaluoma J, Ruskoaho H, Talman V (2018) Stem cells are the most sensitive screening tool to identify toxicity of GATA4-targeted novel small-molecule compounds. Arch Toxicol 92:2897-2911. https://doi.org/10.1007/s00204-018-2257-1

Kawai H, Minamiya Y, Kitamura M, Matsuzaki I, Hashimoto M, Suzuki H, Abo S (1997) Direct measurement of doxorubicin concentration in the intact, living single cancer cell during hyperthermia. Cancer 79:214-219. https://doi.org/10.1002/ (SICI) 1097-0142(19970115)79:2\%3c214:AID-CNCR3 \%3e3.0.CO;2-K

Kerkelä R, Pikkarainen S, Majalahti-Palviainen T, Tokola H, Ruskoaho H (2002) Distinct roles of mitogen-activated protein kinase pathways in GATA4 transcription factor-mediated regulation of B-type natriuretic peptide gene. J Biol Chem 277:13752-13760. https://doi.org/10.1074/jbc.M105736200

Kim Y, Ma AG, Kitta K, Fitch SN, Ikeda T, Ihara Y, Simon AR, Evans T, Suzuki YJ (2003) Anthracycline-induced suppression of GATA4 transcription factor: implication in the regulation of cardiac myocyte apoptosis. Mol Pharmacol 63:368-377. https:// doi.org/10.1124/mol.63.2.368

Kinnunen P, Vuolteenaho O, Uusimaa P, Ruskoaho H (1992) Passive mechanical stretch releases atrial natriuretic peptide from rat ventricular myocardium. Circ Res 70:1244-1253. https://doi. org/10.1161/01.res.70.6.1244

Kinnunen P, Vuolteenaho O, Ruskoaho H (1993) Mechanisms of atrial and brain natriuretic peptide release from rat ventricular myocardium: effect of stretching. Endocrinology 132:1961-1970. https ://doi.org/10.1210/endo.132.5.8477647

Kinnunen SM, Tölli M, Välimäki MJ, Gao E, Szabo Z, Rysä J, Ferreira MPA, Ohukainen P, Serpi R, Correia A, Mäkilä E, Salonen J, Hirvonen J, Santos HA, Ruskoaho H (2018) Cardiac actions of a small molecule inhibitor targeting GATA4-NKX2-5 interaction. Sci Rep 8:4611. https://doi.org/10.1038/s41598-018-22830-8

Kitta K, Day RM, Kim Y, Torregroza I, Evans T, Suzuki YJ (2003) Hepatocyte growth factor induces GATA4 phosphorylation and cell survival in cardiac muscle cells. J Biol Chem 278:4705-4712. https://doi.org/10.1074/jbc.M211616200

Kobayashi S, Lackey T, Huang Y, Bisping E, Pu WT, Boxer LM, Liang Q (2006) Transcription factor GATA4 regulates cardiac BCL2 gene expression in vitro and in vivo. FASEB J 20:800-802. https ://doi.org/10.1096/fj.05-5426fje

Kobayashi S, Volden P, Timm D, Mao K, Xu X, Liang Q (2010) Transcription factor GATA4 inhibits doxorubicin-induced autophagy and cardiomyocyte death. J Biol Chem 285:793-804. https://doi. org/10.1074/jbc.M109.070037

Koka S, Das A, Zhu SG, Durrant D, Xi L, Kukreja RC (2010) Longacting phosphodiesterase-5 inhibitor tadalafil attenuates doxorubicin-induced cardiomyopathy without interfering with chemotherapeutic effect. J Pharmacol Exp Ther 334:1023-1030. https ://doi.org/10.1124/jpet.110.170191

Liang Q, De Windt LJ, Witt SA, Kimball TR, Markham BE, Molkentin JD (2001) The transcription factors GATA4 and GATA6 regulate cardiomyocyte hypertrophy in vitro and in vivo. J Biol Chem 276:30245-30253. https://doi.org/10.1074/jbc.M102174200
Louisse J, Wust RCI, Pistollato F, Palosaari T, Barilari M, Macko P, Bremer S, Prieto P (2017) Assessment of acute and chronic toxicity of doxorubicin in human induced pluripotent stem cellderived cardiomyocytes. Toxicol In Vitro 42:182-190. https://doi. org/10.1016/j.tiv.2017.04.023

Lyu YL, Kerrigan JE, Lin CP, Azarova AM, Tsai YC, Ban Y, Liu LF (2007) Topoisomerase II beta mediated DNA double-strand breaks: implications in doxorubicin cardiotoxicity and prevention by dexrazoxane. Cancer Res 67:8839-8846. https://doi. org/10.1158/0008-5472.CAN-07-1649

Ma KK, Ogawa T, de Bold AJ (2004) Selective upregulation of cardiac brain natriuretic peptide at the transcriptional and translational levels by pro-inflammatory cytokines and by conditioned medium derived from mixed lymphocyte reactions via p38 MAP kinase. J Mol Cell Cardiol 36:505-513. https://doi.org/10.1016/j.yjmcc .2004 .01 .001

Madonna R, Cadeddu C, Deidda M, Mele D, Monte I, Novo G, Pagliaro P, Pepe A, Spallarossa P, Tocchetti CG, Zito C, Mercuro G (2015) Improving the preclinical models for the study of chemotherapyinduced cardiotoxicity: a Position Paper of the Italian Working Group on Drug Cardiotoxicity and Cardioprotection. Heart Fail Rev 20:621-631. https://doi.org/10.1007/s10741-015-9497-4

Maejima Y, Adachi S, Ito H, Hirao K, Isobe M (2008) Induction of premature senescence in cardiomyocytes by doxorubicin as a novel mechanism of myocardial damage. Aging Cell 7:125-136. https ://doi.org/10.1111/j.1474-9726.2007.00358.x

Majalahti T, Suo-Palosaari M, Sarman B, Hautala N, Pikkarainen S, Tokola H, Vuolteenaho O, Wang J, Paradis P, Nemer M, Ruskoaho H (2007) Cardiac BNP gene activation by angiotensin II in vivo. Mol Cell Endocrinol 273:59-67. https://doi.org/10.1016/j. mce.2007.05.003

Morimoto T, Hasegawa K, Kaburagi S, Kakita T, Wada H, Yanazume T, Sasayama S (2000) Phosphorylation of GATA4 is involved in alpha 1-adrenergic agonist-responsive transcription of the endothelin-1 gene in cardiac myocytes. J Biol Chem 275:1372113726. https://doi.org/10.1074/jbc.275.18.13721

Morisco C, Seta K, Hardt SE, Lee Y, Vatner SF, Sadoshima J (2001) Glycogen synthase kinase $3 \beta$ regulates GATA4 in cardiac myocytes. J Biol Chem 276:28586-28597. https://doi.org/10.1074/jbc. M103166200

Mosmann T (1983) Rapid colorimetric assay for cellular growth and survival: application to proliferation and cytotoxicity assays. J Immunol Methods 65:55-63. https://doi.org/10.1016/00221759(83)90303-4

Muller C, Chatelut E, Gualano V, De Forni M, Huguet F, Attal M, Canal P, Laurent G (1993) Cellular pharmacokinetics of doxorubicin in patients with chronic lymphocytic leukemia: comparison of bolus administration and continuous infusion. Cancer Chemother Pharmacol 32:379-384. https://doi.org/10.1007/bf00735923

Octavia Y, Tocchetti CG, Gabrielson KL, Janssens S, Crijns HJ, Moens AL (2012) Doxorubicin-induced cardiomyopathy: from molecular mechanisms to therapeutic strategies. J Mol Cell Cardiol 52:12131225. https://doi.org/10.1016/j.yjmcc.2012.03.006

Ogawa Y, Nakao K, Mukoyama M, Hosoda K, Shirakami G, Arai H, Saito Y, Suga S, Jougasaki M, Imura H (1991) Natriuretic peptides as cardiac hormones in normotensive and spontaneously hypertensive rats. The ventricle is a major site of synthesis and secretion of brain natriuretic peptide. Circ Res 69:491-500. https ://doi.org/10.1161/01.res.69.2.491

Oka T, Maillet M, Watt AJ, Schwartz RJ, Aronow BJ, Duncan SA, Molkentin JD (2006) Cardiac-specific deletion of GATA4 reveals its requirement for hypertrophy, compensation, and myocyte viability. Circ Res 98:837-845. https://doi.org/10.1161/01. RES.0000215985.18538.c4

Park AM, Nagase H, Vinod Kumar S, Suzuki YJ (2007) Acute intermittent hypoxia activates myocardial cell survival signaling. 
Am J Physiol Heart Circ Physiol 292:H751-H757. https://doi. org/10.1152/ajpheart.01016.2006

Park AM, Nagase H, Liu L, Vinod Kumar S, Szwergold N, Wong CM, Suzuki YJ (2011) Mechanism of anthracycline-mediated downregulation of GATA4 in the heart. Cardiovasc Res 90:97-104. https://doi.org/10.1093/cvr/cvq361

Pikkarainen S, Tokola H, Majalahti-Palviainen T, Kerkelä R, Hautala N, Bhalla SS, Charron F, Nemer M, Vuolteenaho O, Ruskoaho $\mathrm{H}$ (2003) GATA4 is a nuclear mediator of mechanical stretchactivated hypertrophic program. J Biol Chem 278:23807-23816. https://doi.org/10.1074/jbc.M302719200

Pikkarainen S, Tokola H, Kerkelä R, Ruskoaho H (2004) GATA transcription factors in the developing and adult heart. Cardiovasc Res 63:196-207. https://doi.org/10.1016/j.cardiores.2004.03.025

Renu K, Abilash VG, Tirupathi Pichiah PB, Arunachalam S (2018) Molecular mechanism of doxorubicin-induced cardiomyopathy-an update. Eur J Pharmacol 818:241-253. https://doi. org/10.1016/j.ejphar.2017.10.043

Riad A, Bien S, Gratz M, Escher F, Westermann D, Heimesaat MM, Bereswill S, Krieg T, Felix SB, Schultheiss HP, Kroemer HK, Tschope C (2008) Toll-like receptor-4 deficiency attenuates doxorubicin-induced cardiomyopathy in mice. Eur J Heart Fail 10:233-243. https://doi.org/10.1016/j.ejheart.2008.01.004

Rochette L, Guenancia C, Gudjoncik A, Hachet O, Zeller M, Cottin Y, Vergely C (2015) Anthracyclines/trastuzumab: new aspects of cardiotoxicity and molecular mechanisms. Trends Pharmacol Sci 36:326-348. https://doi.org/10.1016/j.tips.2015.03.005

Ruskoaho H (2003) Cardiac hormones as diagnostic tools in heart failure. Endocr Rev 24:341-356. https://doi.org/10.1210/ er.2003-0006

Rysä J, Tenhunen O, Serpi R, Soini Y, Nemer M, Leskinen H, Ruskoaho H (2010) GATA4 is an angiogenic survival factor of the infarcted heart. Circ Heart Fail 3:440-450. https://doi. org/10.1161/CIRCHEARTFAILURE.109.889642

Senkus E, Jassem J (2011) Cardiovascular effects of systemic cancer treatment. Cancer Treat Rev 37:300-311. https://doi. org/10.1016/j.ctrv.2010.11.001

Speth PA, Linssen PC, Boezeman JB, Wessels HM, Haanen C (1987) Cellular and plasma adriamycin concentrations in long-term infusion therapy of leukemia patients. Cancer Chemother Pharmacol 20:305-310. https://doi.org/10.1007/bf00262581

Suzuki YJ (2011) Cell signaling pathways for the regulation of GATA4 transcription factor: implications for cell growth and apoptosis. Cell Signal 23:1094-1099. https://doi.org/10.1016/j.cells ig.2011.02.007

Tölli MA, Ferreira MP, Kinnunen SM, Rysä J, Mäkilä EM, Szabo Z, Serpi RE, Ohukainen PJ, Välimäki MJ, Correia AM, Salonen JJ, Hirvonen JT, Ruskoaho HJ, Santos HA (2014) In vivo biocompatibility of porous silicon biomaterials for drug delivery to the heart. Biomaterials 35:8394-8405. https://doi.org/10.1016/j.biomateria 1s.2014.05.078
Toth M, Vuorinen KH, Vuolteenaho O, Hassinen IE, Uusimaa PA, Leppäluoto J, Ruskoaho H (1994) Hypoxia stimulates release of ANP and BNP from perfused rat ventricular myocardium. Am J Physiol 266:H1572-H1580. https://doi.org/10.1152/ajphe art.1994.266.4.H1572

Tremblay M, Sanchez-Ferras O, Bouchard M (2018) GATA transcription factors in development and disease. Development. https://doi. org/10.1242/dev.164384

Välimäki MJ, Tölli MA, Kinnunen SM, Aro J, Serpi R, Pohjolainen L, Talman V, Poso A, Ruskoaho HJ (2017) Discovery of small molecules targeting the synergy of cardiac transcription factors GATA4 and NKX2-5. J Med Chem 60:7781-7798. https://doi. org/10.1021/acs.jmedchem.7b00816

van Berlo JH, Elrod JW, Aronow BJ, Pu WT, Molkentin JD (2011) Serine 105 phosphorylation of transcription factor GATA4 is necessary for stress-induced cardiac hypertrophy in vivo. Proc Natl Acad Sci USA 108:12331-12336. https://doi.org/10.1073/ pnas. 1104499108

Vejpongsa P, Yeh ET (2014) Prevention of anthracycline-induced cardiotoxicity: challenges and opportunities. J Am Coll Cardiol 64:938-945. https://doi.org/10.1016/j.jacc.2014.06.1167

Yang F, Teves SS, Kemp CJ, Henikoff S (2014) Doxorubicin, DNA torsion, and chromatin dynamics. Biochim Biophys Acta 1845:8489. https://doi.org/10.1016/j.bbcan.2013.12.002

Yu J, Vodyanik MA, Smuga-Otto K, Antosiewicz-Bourget J, Frane JL, Tian S, Nie J, Jonsdottir GA, Ruotti V, Stewart R, Slukvin II, Thomson JA (2007) Induced pluripotent stem cell lines derived from human somatic cells. Science 318:1917-1920. https://doi. org/10.1126/science. 1151526

Zamorano JL, Lancellotti P, Rodriguez Munoz D, Aboyans V, Asteggiano R, Galderisi M, Habib G, Lenihan DJ, Lip GYH, Lyon AR, Lopez Fernandez T, Mohty D, Piepoli MF, Tamargo J, Torbicki A, Suter TM, ESC Scientific Document Group (2016) 2016 ESC Position Paper on cancer treatments and cardiovascular toxicity developed under the auspices of the ESC Committee for Practice Guidelines: the Task Force for cancer treatments and cardiovascular toxicity of the European Society of Cardiology (ESC). Eur Heart J 37:2768-2801. https://doi.org/10.1093/eurheartj/ehw211

Zhang S, Liu X, Bawa-Khalfe T, Lu LS, Lyu YL, Liu LF, Yeh ET (2012) Identification of the molecular basis of doxorubicininduced cardiotoxicity. Nat Med 18:1639-1642. https://doi. org/10.1038/nm.2919

Zhao L, Zhang B (2017) Doxorubicin induces cardiotoxicity through upregulation of death receptors mediated apoptosis in cardiomyocytes. Sci Rep 7:44735. https://doi.org/10.1038/srep44735

Publisher's Note Springer Nature remains neutral with regard to jurisdictional claims in published maps and institutional affiliations. 